\title{
The Mass of the Black Hole in Cygnus X-1
}

\section{Citation}

Orosz, Jerome A., Jeffrey E. McClintock, Jason P. Aufdenberg, Ronald A. Remillard, Mark J. Reid, Ramesh Narayan, and Lijun Gou. 2011. "The Mass of the Black Hole in Cygnus X-1." The Astrophysical Journal 742, no. 2: 84.

\section{Published Version}

doi:10.1088/0004-637X/742/2/84

\section{Permanent link}

http://nrs.harvard.edu/urn-3:HUL.InstRepos:13041328

\section{Terms of Use}

This article was downloaded from Harvard University's DASH repository, and is made available under the terms and conditions applicable to Other Posted Material, as set forth at http:// nrs.harvard.edu/urn-3:HUL.InstRepos:dash.current.terms-of-use\#LAA

\section{Share Your Story}

The Harvard community has made this article openly available.

Please share how this access benefits you. Submit a story.

Accessibility 


\title{
THE MASS OF THE BLACK HOLE IN CYGNUS X-1
}

\author{
Jerome A. Orosz ${ }^{1}$, Jeffrey E. McClintock ${ }^{2}$, Jason P. Aufdenberg ${ }^{3}$, Ronald A. Remillard ${ }^{4}$, \\ MARK J. REID ${ }^{2}$, RAMESH NARAYAN ${ }^{2}$, AND LIJUN GOU ${ }^{2}$ \\ ${ }^{1}$ Department of Astronomy, San Diego State University, San Diego, CA 92182-1221, USA; orosz@ @siences.sdsu.edu \\ ${ }^{2}$ Harvard-Smithsonian Center for Astrophysics, Cambridge, MA 02138, USA; \\ jem@cfa.harvard.edu, reid@cfa.harvard.edu,narayan@cfa.harvard.edu, lgou@cfa.harvard.edu \\ ${ }^{3}$ Physical Sciences Department, Embry-Riddle Aeronautical University, Daytona Beach, FL 32114, USA; aufded93@erau.edu \\ ${ }^{4}$ Kavli Institute for Astrophysics and Space Research, Massachusetts Institute of Technology, Cambridge, MA 02139-4307, USA; rr@space.mit.edu \\ Received 2011 June 17; accepted 2011 September 30; published 2011 November 9
}

\begin{abstract}
Cygnus X-1 is a binary star system that is comprised of a black hole and a massive giant companion star in a tight orbit. Building on our accurate distance measurement reported in the preceding paper, we first determine the radius of the companion star, thereby constraining the scale of the binary system. To obtain a full dynamical model of the binary, we use an extensive collection of optical photometric and spectroscopic data taken from the literature. By using all of the available observational constraints, we show that the orbit is slightly eccentric (both the radial velocity and photometric data independently confirm this result) and that the companion star rotates roughly 1.4 times its pseudosynchronous value. We find a black hole mass of $M=14.8 \pm 1.0 M_{\odot}$, a companion mass of $M_{\mathrm{opt}}=19.2 \pm 1.9 M_{\odot}$, and the angle of inclination of the orbital plane to our line of sight of $i=27.1 \pm 0.8 \mathrm{deg}$.
\end{abstract}

Key words: binaries: general - black hole physics - stars: individual (Cygnus X-1) - X-rays: binaries

Online-only material: color figure

\section{INTRODUCTION}

During the past 39 years, many varied estimates have been made of the mass $M$ of the black hole in Cygnus X-1. At one extreme, acting as a devil's advocate against black hole models, Trimble et al. (1973) proposed a model based on a distance $D \sim 1 \mathrm{kpc}$ which gave a low mass of $M \lesssim 1 M_{\odot}$, suggestive of a neutron star or a white dwarf, not a black hole. Several other low-mass models were summarized, considered, and found wanting by Bolton (1975). By contrast, all conventional binary models that assume the secondary companion is a massive O-type supergiant find a large - but uncertain - mass for the compact object that significantly exceeds the maximum stable mass for a neutron star of $\approx 3 M_{\odot}$ (Kalogera \& Baym 1996), hence requiring a black hole. For example, using geometrical arguments, Paczyński (1974) computed the minimum mass for the compact object as a function of the distance and found $M>3.6 M_{\odot}$ for $D>1.4 \mathrm{kpc}$. Based on dynamical modeling, Gies \& Bolton (1986) found $M>7 M_{\odot}$ and a probable mass of $M_{\mathrm{opt}}=16 M_{\odot}$ for the companion star, and Ninkov et al. (1987) found $M=10 \pm 1 M_{\odot}$ (by assuming $M_{\mathrm{opt}}=20 M_{\odot}$ ).

However, these mass estimates, and all such estimates that have been made to date, are very uncertain because they are based on unsatisfactory estimates of the distance to Cygnus X-1 (Reid et al. 2011). The strong effect of distance on the model parameters is obvious from an inspection of Table 4 in Caballero-Nieves et al. (2009; and also Table 1 of Paczyński 1974). For the dynamical model favored by Caballero-Nieves et al. (2009), and over the wide range of distances they consider, $1.1-2.5 \mathrm{kpc}$, the radius of the companion star and the mass of the black hole are seen to vary by factors of 2.3 and 11.7, respectively. Thus, in order to obtain useful constraints on the system parameters, it is essential to have an accurate value of the source distance, as we have demonstrated for two extragalactic black hole systems that contain O-type supergiants, M33 X-7 (Orosz et al. 2007) and LMC X-1 (Orosz et al. 2009), whose distances are known to several percent accuracy via the cosmic distance ladder.

In this paper, we use a distance from a trigonometric parallax measurement for Cygnus X-1 (Reid et al. 2011), which is accurate to $\pm 6 \%$, and previously published optical data to build a complete dynamical model of the Cygnus X-1 binary system. We are not only able to strongly constrain the principal parameters of the system, but also obtain the first constraints on the orbital eccentricity, $e$, and the deviation of the period of rotation of the companion star from the orbital period, characterized by the nonsynchronous rotation parameter, $\Omega$ (Orosz et al. 2009). Of principal interest are our precise determinations of the black hole mass $M$ and the orbital inclination angle $i$. As we show in the paper that follows (Gou et al. 2011), our accurate values for the three parameters $M, i$, and $D$ are the keys to determining the spin of the black hole.

\section{DYNAMICAL MODELING}

The mass of the black hole can be easily determined once we know both its distance from the center of mass of the O-star and the orbital velocity of the star. Since optical spectroscopy only gives us the radial component of velocity, we must also determine the inclination of the orbital plane relative to our line of sight in order to infer the orbital velocity. Furthermore, since the star orbits the center of mass of the system, we must also obtain the separation between the two components. We determine the needed quantities using our comprehensive modeling code (Orosz \& Hauschildt 2000). Our model, which is underpinned by our new measurement of the distance, makes use of all relevant observational constraints in a self-consistent manner. We discuss details of the data and modeling below.

\subsection{Optical Data Selection}

There is no shortage of published observational data for Cygnus X-1 in the literature. Brocksopp et al. (1999b) provide 
$U, B$, and $V$ light curves containing nearly 27 years worth of observations (1971-1997) from the Crimean Laboratory of the Sternberg Astronomical Institute. The binned light curves contain 20 points each and are phased on the following ephemeris:

Min I $=\mathrm{JD} 2441163.529( \pm 0.009)+5.599829( \pm 0.000016) E$,

where Min $I$ is the time of the inferior conjunction of the O-star and $E$ is the cycle number. In addition, Brocksopp et al. (1999b) provide 421 radial velocity measurements, which are phased to the same ephemeris. The light and velocity curves were kindly sent to us by $\mathrm{C}$. Brocksopp.

In addition to the velocity data of Broscksopp et al., we also made use of the radial velocities published by Gies et al. (2003). We fitted a sine curve to their data and those of Brocksopp et al. (1999a). Fixing the uncertainties on the individual velocity measurements to $7.47 \mathrm{~km} \mathrm{~s}^{-1}$ and $5.06 \mathrm{~km} \mathrm{~s}^{-1}$, respectively (these values give $\chi^{2} \approx N$ ), we found $K=74.46 \pm 0.51 \mathrm{~km} \mathrm{~s}^{-1}$ for the Brocksopp et al. data and $K=75.57 \pm 0.70 \mathrm{~km} \mathrm{~s}^{-1}$ for the Gies et al. data. The $1 \sigma$ intervals of the respective $K$-velocities overlap, the residuals of the fits show no obvious structure, and there is no notable difference between the residuals of the two data sets, apart from the slightly greater scatter in the Brocksopp et al. data. We therefore combined the two sets of radial velocities while removing the respective systemic velocities from the individual sine curves. We phased the Gies et al. data on the above ephemeris before merging these data with the velocity data of Broscksopp et al. The combined data set has 529 points.

All of these velocity and light curve data are discussed further and analyzed in Section 2.4, where they are shown folded on the orbital period and seen to exhibit minimal scatter about the model fits. This small scatter in these data sets, each spanning a few decades, attests to the strongly dominant orbital component of variability. Meanwhile, Cygnus X-1 is well known to be variable in the radio and $\mathrm{X}$-ray bands, including major transitions between hard and soft X-ray states (see Figure 1 in Gou et al. 2011). This raises the question of whether any non-orbital variability in the light curve data could significantly affect the component masses and other parameters determined by our model. (We focus on the light curve data, which are more susceptible to being affected by variability.)

We believe that our results are robust to such non-orbital variability for several reasons, including the following. (1) While Brocksopp et al. (1999a) note that the $U, B$, and $V$ light curves were correlated with each other, they found no correlation with the radio and $\mathrm{X}$-ray light curves, which is reasonable given that the time-averaged bolometric X-ray luminosity is only $\lesssim 0.3 \%$ of the bolometric luminosity of the O-star (Section 2.3). (2) Although Brocksopp et al. (1999b) did not specifically discuss the photometric variability seen in their 27 year data set, Brocksopp et al. (1999a) do discuss the multiwavelength variability of the source over a 2.5 year period. They noted that there is very little variability in the optical light curves apart from the dominant ellipsoidal/orbital modulations (see Section 2.4) and one weaker modulation with about half the amplitude on a 142 day period (which is thought to be related to the precession of the accretion disk). (3) The light curve and velocity data give remarkably consistent results for the small (but statistically very significant) measured values of eccentricity and argument of periastron (Section 2.4.2). (4) As highlighted above, the small scatter in the folded light curves for a data set spanning 27 years is strong evidence against a significant component of variability on timescales other than the orbital period. In summary, we

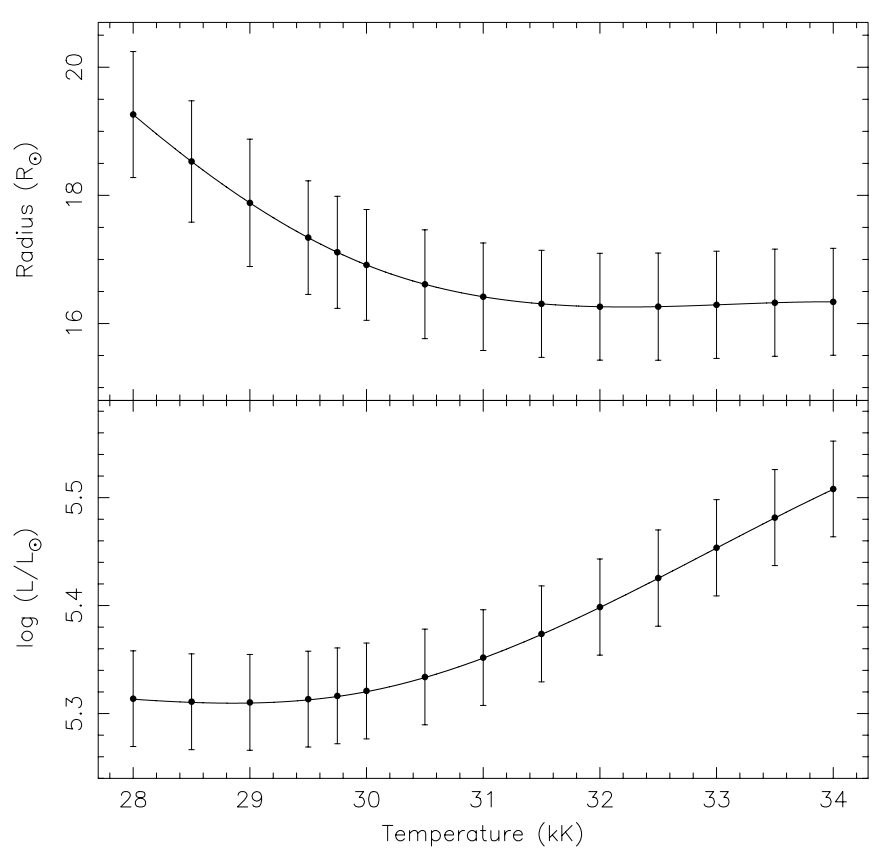

Figure 1. Derived O-star radius (top) and luminosity (bottom) as a function of the assumed effective temperature.

conclude that non-orbital variability is unlikely to significantly affect our results.

\subsection{Stellar Radius, Temperature, and Rotational Velocity}

In order to constrain the dynamical model, it is crucial to have a good estimate of the radius of the companion star. However, customary methods of determining this radius fail because the Cygnus X-1 system does not exhibit eclipses nor does the companion star fill its Roche equipotential lobe. We obtain the required estimate of the stellar radius as we have done previously in our study of LMC X-1 (Orosz et al. 2009). The radius, which critically depends on distance, additionally depends on the apparent magnitude of the O-type star and interstellar extinction, and also on the effective stellar temperature and corresponding bolometric correction. The absolute magnitude of the star is $M_{\mathrm{abs}}=K+\mathrm{BC}_{K}\left(T_{\mathrm{eff}}, g\right)-(5 \log D-5)-0.11 A_{V}$, where $K$ is the apparent $K$-band magnitude, $\mathrm{BC}_{K}$ is the bolometric correction for the $K$ band, $D$ is the distance, and $A_{V}$ is the extinction in the $V$ band. The luminosity and radius of the star in solar units are $L=10^{-0.4\left(M_{\mathrm{abs}}-4.71\right)}$ and $R=\sqrt{L\left(5770 / T_{\mathrm{eff}}\right)^{4}}$, respectively. In computing these quantities, we use $D=1.86_{-0.11}^{+0.12}$ kpc (Reid et al. 2011) and a $K$-band apparent magnitude of $K=$ $6.50 \pm 0.02$ (Skrutskie et al. 2006), which minimizes the effects of interstellar extinction. For the $K$-band extinction, we adopt $E(B-V)=1.11 \pm 0.03$ and $R_{V}=3.02 \pm 0.03$ (e.g., $A_{V}=$ 3.35, Caballero-Nieves et al. 2009) and use the standard extinction law (Cardelli et al. 1989). The bolometric corrections for the $K$ band were computed using the OSTAR2002 grid of models with solar metallicity (Lanz \& Hubeny 2003). We note that the $K$-band bolometric corrections for the solar metallicity models and the models for half-solar metallicity differ only by $0.02 \mathrm{dex}$ (T. Lanz 2007, private communication), so our results are not sensitive to the metallicity.

Figure 1 shows the derived radius and luminosity of the star as a function of its assumed temperature in the range $28,000 \mathrm{~K} \leqslant T_{\text {eff }} \leqslant 34,000 \mathrm{~K}$. For $T_{\text {eff }}=28,000$, the radius 
is $R_{\text {dist }}=19.26 \pm 0.98 R_{\odot} \cdot{ }^{5}$ As the temperature increases, the radius decreases rapidly at first, and then it plateaus midway through the range, attaining a value of $R_{\text {dist }}=16.34 \pm 0.84 R_{\odot}$ at $T_{\text {eff }}=34,000 \mathrm{~K}$. Meanwhile, the luminosity increases with temperature, rising from $L=2.1 \times 10^{5} L_{\odot}$ at $T_{\text {eff }}=28,000 \mathrm{~K}$ to $L=3.2 \times 10^{5} L_{\odot}$ at $T_{\text {eff }}=34,000 \mathrm{~K}$.

The effective temperature of the companion star can be determined from a detailed analysis of UV and optical line spectra (Herrero et al. 1995; Karitskaya et al. 2005; Caballero-Nieves et al. 2009). However, it is often difficult to determine a precise temperature for O-type stars owing to a correlation between the effective temperature $T_{\text {eff }}$ and the surface gravity parameter $\log g$. Model atmospheres with slightly smaller values of $T_{\text {eff }}$ and $\log g$ give spectra that are very similar to those obtained for slightly higher values of these parameters. Fortunately, $\log g$ for the companion star in Cygnus X-1 is tightly constrained for a wide range of assumptions about the temperature, mass ratio, and other parameters because of a peculiarity of Roche-lobe geometry (Eggleton 1983). We show below that our dynamical model constrains the value of the surface gravity to lie in the range $\log g=3.30-3.45$ (where $g$ is in $\mathrm{cm} \mathrm{s}^{-2}$ ).

Based on an analysis of both optical and UV spectra, Caballero-Nieves et al. (2009) obtained for their favored model $T_{\text {eff }}=28,000 \pm 2500 \mathrm{~K}$ and a surface gravity $\log g \gtrsim$ $3.00 \pm 0.25$, which is outside the range of values implied by our model. Based on the plots and tables in CaballeroNieves et al. (2009), we estimate a best-fitting temperature of $T_{\text {eff }}=30,000 \pm 2500 \mathrm{~K}$ when the surface gravity is forced to lie in the range determined by our dynamical model. Using optical spectra, Karitskaya et al. (2005) found $T_{\text {eff }}=30,400 \pm$ $500 \mathrm{~K}$ and $\log g=3.31 \pm 0.07$, which is consistent with our dynamically determined value. Likewise, Herrero et al. (1995) report $T_{\text {eff }}=32,000$ and $\log g=3.21$ (no uncertainties are given in their Table 1). In the following, we adopt a temperature range of $30,000 \mathrm{~K} \leqslant T_{\text {eff }} \leqslant 32,000 \mathrm{~K}$.

After considering several previous determinations of the projected rotational velocity of the O-type star and corrections for macroturbulent broadening, Caballero-Nieves et al. (2009) adopt $V_{\text {rot }} \sin i=95 \pm 6 \mathrm{~km} \mathrm{~s}^{-1}$. We use this value as a constraint on our dynamical model, which we now discuss.

\subsection{ELC Description and Model Parameters}

The eclipsing light curve (ELC) model (Orosz \& Hauschildt 2000) has parameters related to the system geometry and parameters related to the radiative properties of the star. For the Cygnus X-1 models, the orbital period is fixed at $P=5.599829$ days (Brocksopp et al. 1999b). Once the values of $P$, the $K$-velocity of the O-star, and the O-star's mass $M_{\text {opt }}$ are known, the scale size of the binary (e.g., the semimajor axis $a$ ) and the mass of the black hole $M$ are uniquely determined. With the scale of the binary set, the radius of the star $R_{\text {opt }}$ determines the Roche-lobe filling fraction $\rho$. Not all values of $R_{\text {opt }}$ are allowed (for a given $P, M_{\mathrm{opt}}$, and $K$ ): if $R_{\mathrm{opt}}$ exceeds the effective radius of the O-star's Roche lobe, we then set the value of $\rho$ to unity.

The main parameters that control the radiative properties of the $\mathrm{O}$-star are its effective temperature $T_{\text {eff }}$, its gravity darkening exponent $\beta$, and its bolometric albedo $A$. Following standard practice for a star with a radiative outer envelope, we set $\beta=0.25$ and $A=1$.

\footnotetext{
5 We use the notation $R_{\text {dist }}$ to denote the stellar radius derived from the parallax distance and $R_{\mathrm{opt}}$ to denote the stellar radius derived from the dynamical model.
}

The ELC model can also include optical light from a flared accretion disk. In the case of Cygnus X-1, the O-star dominates the optical and UV flux (Caballero-Nieves et al. 2009), where the ratio of stellar flux to accretion disk flux at $5000 \AA$ is about 10,000. Consequently, we do not include any optical light from an accretion disk.

We turn to the question of the X-ray heating of the supergiant star and its effect on the binary model. The X-ray heating is computed using the technique outlined in Wilson (1990). The $\mathrm{X}$-ray source geometry is assumed to be a thin disk in the orbital plane with a radius vanishingly small compared to the semimajor axis (this structure should not be confused with the much larger accretion disk that potentially could be a source of optical flux). Points on the stellar surface "see" the X-ray source at inclined angles and the proper foreshortening is accounted for.

Measurement of the broadband X-ray luminosity of Cygnus X-1 $\left(L_{\mathrm{xbol}}\right.$; hereafter in units of $10^{37} \mathrm{erg} \mathrm{s}^{-1}$, adjusted to the revised distance of $1.86 \mathrm{kpc}$ ) requires special instrumentation and considerations. There are soft and hard states of Cygnus X-1 (e.g., Gou et al. 2011). The hard state is especially challenging because the effective temperature of the accretion disk is relatively low $(T<0.5 \mathrm{keV})$, while the hard power-law component (with photon index $\sim 1.7$ ) must be integrated past the cutoff energy $\sim 150 \mathrm{keV}$ (Gierlinski et al. 1997; Cadolle Bel et al. 2006). Since the ground-based observations (i.e., photometric data and radial velocity measurements) are distributed over many years, both the range and the long-term average of the $\mathrm{X}$-ray luminosity must be estimated.

The archive of the Rossi X-ray Timing Explorer (RXTE) contains several thousand observations of Cygnus X-1 collected in numerous monitoring campaigns conducted over the life of the mission. We processed and analyzed 2343 exposure intervals (1996 January to 2011 February; mean exposure $2.2 \mathrm{ks}$ ) with the Proportional Counter Array (PCA) instrument and we then computed normalized light curves in four energy bands $(2-18 \mathrm{keV})$ in the manner described by Remillard \& McClintock (2006). In the hardness-intensity diagram, the soft and hard states of Cyg X-1 can be separated by the value of hard color (HC; i.e., the ratio of the normalized PCA count rates at 8.6-18.0 versus $5.0-8.6 \mathrm{keV}$ ), using a simple discrimination line at $\mathrm{HC}=0.7$. Based on this, we determine that Cygnus $\mathrm{X}-1$ is found to be in the hard state $73 \%$ of the time.

Zhang et al. (1997) studied the broadband spectra of Cygnus $\mathrm{X}-1$ with instruments of RXTE and the Compton Gamma Ray Observatory. During the hard and soft states of 1996, they found broadband X-ray luminosities in the range 1.6-2.2 for the hard state and 2.2-3.3 for the soft state. Samples of the hard and intermediate states during 2002-2004 with the International Gamma-Ray Astrophysics Laboratory yielded $L_{\mathrm{xbol}}$ in the range 1.2-2.0 (Cadolle Bel et al. 2006). Additional measurements of the soft state with BeppoSAX (Frontera et al. 2001) found $L_{\mathrm{xbol}}$ in the range 1.7-2.1, while Gou et al. (2011) analyzed bright soft state observations by ASCA and RXTE (1996) or Chandra and $R X T E$ (2010) to determine $L_{\mathrm{xbol}}$ in the range 3.2-4.0.

To get a rough idea of how these special observations relate to typical conditions, we used the available contemporaneous $R X T E$ observations to scale the measured $L_{\mathrm{xbol}}$ values against the PCA count rates, considering hard and soft states separately. We then estimated that the average hard and soft states would correspond to $L_{\text {xbol }}$ values of 1.9 and 3.3, respectively. Finally, the time-averaged luminosity would then be roughly $2.1 \times$ $10^{37} \mathrm{erg} \mathrm{s}^{-1}$, which corresponds to 0.01 of the Eddington limit for Cygnus X-1. This value is much smaller than the bolometric 
luminosity of the $\mathrm{O}$-star $\left(L_{\mathrm{Bol}} \approx 7.94 \times 10^{39} \mathrm{erg} \mathrm{s}^{-1}\right)$, and so we expect that $\mathrm{X}$-ray heating in Cygnus $\mathrm{X}-1$ will not be a significant source of systematic error. We ran some simple tests in which we increased the bolometric X-ray luminosity by up to an order of magnitude and found the light curves to be essentially identical.

When computing the light curve, ELC integrates the various intensities of the visible surface elements on the star. At a given phase and viewing angle, each surface element on the star has a temperature $T$, a gravity $\log g$, and a viewing angle $\mu=\cos \theta$, where $\theta$ is the angle between the surface normal and the line of sight. ELC has a pre-computed table of specific intensities for a grid of models in the $T_{\text {eff }}-\log g$ plane. Consequently, no parameterized limb darkening law is needed. For the specific case of Cygnus X-1, the range of temperature-gravity pairs on the star contained points that are outside the OSTAR2002+BSTAR2006 model grids (Lanz \& Hubeny 2003, 2007). We therefore computed a new grid of models, assuming solar metallicity. The range in effective temperature is from $12,000 \mathrm{~K}$ to $40,000 \mathrm{~K}$ in steps of $1000 \mathrm{~K}$, and the range in the logarithm of the surface gravity $\log g\left(\mathrm{~cm} \mathrm{~s}^{-2}\right)$ is from 2.00 to 3.75 in steps of 0.25 dex. The wavelengthdependent radiation fields $I_{\lambda}(\mu)$, as a function of the cosine of the emergent angle $\mu$, were computed from 232 spherical, line-blanketed, LTE models using the generalized model stellar atmosphere code PHOENIX, version 15.04.00E (Aufdenberg et al. 1998). These models take into consideration between $1,176,932$ and 2,296,243 atomic lines in the computation of the line opacity. The radiation fields were computed at 26,639 wavelengths between $0.1 \mathrm{~nm}$ and $900,000 \mathrm{~nm}$ and at 228 angle points at the outer boundary of each model structure. The models include 100 depth points, an outer pressure boundary of $10^{-4} \mathrm{dyn} \mathrm{cm}^{-2}$, an optical depth range (in the continuum at $500 \mathrm{~nm}$ ) from $10^{-10}$ to $10^{2}$, a microturbulence of $2.0 \mathrm{~km} \mathrm{~s}^{-1}$, and they have a radius of $18 R_{\odot}$. (At the gravities of interest, the models are very insensitive to the precise value of the stellar radius.) A table of filter-integrated specific intensities for the Johnson $U, B$, and $V$ filters for use in ELC was prepared in the manner described in Orosz \& Hauschildt (2000).

As noted above, the observational data we model include the $U, B$, and $V$ light curves from Brocksopp et al. (1999b), and the radial velocities from Brocksopp et al. (1999b) and Gies et al. (2003), which are combined into one set. We use the standard $\chi^{2}$ statistic to measure the goodness of fit of the models:

$$
\begin{gathered}
\chi_{\text {data }}^{2}=\sum_{i=1}^{20}\left(\frac{U_{i}-U_{\text {mod }}(\vec{a})}{\sigma_{i}}\right)^{2}+\sum_{i=1}^{20}\left(\frac{B_{i}-B_{\text {mod }}(\vec{a})}{\sigma_{i}}\right)^{2} \\
+\sum_{i=1}^{20}\left(\frac{V_{i}-V_{\text {mod }}(\vec{a})}{\sigma_{i}}\right)^{2}+\sum_{i=1}^{529}\left(\frac{R V_{i}-R V_{\text {mod }}(\vec{a})}{\sigma_{i}}\right)^{2} .
\end{gathered}
$$

Here, the notation $U_{i}$ refers to the observed $U$ magnitude at a given phase $i ; \sigma_{i}$ is the uncertainty and $U_{\bmod }(\vec{a})$ is the model magnitude at that same phase, given a set of fitting parameters $\vec{a}$. A similar notation is used for the $B$ and $V$ bands, and for the radial velocities.

Initially we assumed a circular orbit and synchronous rotation, which left us with five free parameters: the orbital inclination angle $i$, the amplitude $K$ of the O-star's radial velocity curve (the " $K$-velocity"), the mass of the star $M_{\mathrm{opt}}$, the radius of the star $R_{\mathrm{opt}}$, and a small phase shift parameter $\phi$ to account for slight errors in the ephemerides. We quickly found, upon an examination of the post-fit residuals, that circular/synchronous models are inadequate and more complex models are required.
In the end, we computed four classes of models. (1) Model A has a circular orbit and synchronous rotation, and it uses the five free parameters discussed above: $\vec{a}=\left(i, k, M_{\mathrm{opt}}, R_{\mathrm{opt}}, \phi\right)$. (2) Model B has a circular orbit and nonsynchronous rotation, requiring one additional free parameter $\Omega$, which is the ratio of the rotational frequency of the O-star to the orbital frequency: $\vec{a}=\left(i, k, M_{\mathrm{opt}}, R_{\mathrm{opt}}, \phi, \Omega\right)$. (3) Model $\mathrm{C}$ has an eccentric orbit and synchronous rotation at periastron. For this model there are seven free parameters, namely the five parameters for Model A plus the eccentricity $e$ and the argument of periastron $\omega: \vec{a}=\left(i, k, M_{\mathrm{opt}}, R_{\mathrm{opt}}, \phi, e, \omega\right)$. Finally, (4) Model $\mathrm{D}$ incorporates the possibility of nonsynchronous rotation and an eccentric orbit and has a total of eight free parameters: $\vec{a}=\left(i, k, M_{\mathrm{opt}}, R_{\mathrm{opt}}, \phi, e, \omega, \Omega\right)$.

We also have additional observed constraints that do not apply to a given orbital phase, but rather to the system as a whole. These include the stellar radius (computed from the parallax distance $R_{\text {dist }}$ for a given temperature) and the rotational velocity of $V_{\text {rot }} \sin i=95 \pm 6 \mathrm{~km} \mathrm{~s}^{-1}$. For Cygnus $\mathrm{X}-1$, $\mathrm{X}$-ray eclipses are not observed and hence there is no eclipse constraint. As discussed in Orosz et al. (2002), the radius and velocity constraints are imposed by adding additional terms to the value of $\chi^{2}$ :

$$
\chi_{\mathrm{con}}^{2}=\left(\frac{R_{\mathrm{opt}}-R_{\mathrm{dist}}}{\sigma_{R_{\mathrm{dist}}}}\right)^{2}+\left(\frac{V_{\mathrm{rot}} \sin i-95}{6}\right)^{2} .
$$

Finally, for a given model, we have as our ultimate measure of the goodness of fit

$$
\chi_{\text {tot }}^{2}=\chi_{\text {data }}^{2}+\chi_{\text {con }}^{2} .
$$

As with any fitting procedure, some care must be taken when considering relative weights of various data sets. In the case of Cygnus X-1, the quality of the light curves is similar in all three bands. We therefore scaled the uncertainties by small factors in order to get $\chi^{2} \approx N$ for each set separately. This resulted in mean uncertainties of $0.00341 \mathrm{mag}$ for $U, 0.00155 \mathrm{mag}$ for $B$, and 0.00226 for $V$. The uncertainties for the radial velocity measurements are given in Section 2.1.

\subsection{ELC Fitting \\ 2.4.1. Principal Results}

The fits to the light curve and radial velocity data for Model A (left panels) and Model D (right panels) are shown in Figure 2, and the best-fit values of the parameters are given for all four models in Table 1 . These results are for $T_{\text {eff }}=31,000 \mathrm{~K}$; similar figures and tables for other temperatures are presented in the Appendix. For a given temperature, the tabular data reveal a key trend: the total $\chi^{2}$ of the fit rapidly decreases as one goes from Model A to Model D, indicating that eccentricity and nonsynchronous rotation are important elements, and we therefore adopt Model D. For final values of the fitted and derived parameters given in Table 2, we take the weighted average of the values derived for each of the temperatures in the range $30,000 \mathrm{~K} \leqslant T_{\text {eff }} \leqslant 32,000 \mathrm{~K}$. A schematic diagram of the binary based on our best-fitting model is shown in Figure 3.

\subsubsection{Need for Non-zero Eccentricity}

In our dynamical model, the orbit is not quite circular and the stellar rotation is not synchronous at periastron. Although eccentric orbits based on light curve models have been considered in the past (e.g., Hutchings 1978; Guinan et al. 1979), most 
Table 1

Cygnus X-1 Model Parameters

\begin{tabular}{|c|c|c|c|c|c|}
\hline Parameter & Model A & Model B & Model C & Model D & Adopted \\
\hline$i(\operatorname{deg})$ & $51.45 \pm 7.46$ & $67.74 \pm 2.83$ & $28.50 \pm 2.21$ & $27.03 \pm 0.41$ & $27.06 \pm 0.76$ \\
\hline$\Omega$ & 1.000 & $0.674 \pm 0.043$ & 1.000 & $1.404 \pm 0.099$ & $1.400 \pm 0.084$ \\
\hline$e$ & $\ldots$ & $\ldots$ & $0.025 \pm 0.003$ & $0.018 \pm 0.002$ & $0.018 \pm 0.003$ \\
\hline$\omega(\mathrm{deg})$ & $\ldots$ & $\ldots$ & $303.5 \pm 5.1$ & $308.1 \pm 5.5$ & $307.6 \pm 5.3$ \\
\hline$M_{\mathrm{opt}}\left(M_{\odot}\right)$ & $20.53 \pm 2.00$ & $26.27 \pm 2.41$ & $25.17 \pm 2.54$ & $18.97 \pm 2.15$ & $19.16 \pm 1.90$ \\
\hline$M\left(M_{\odot}\right)$ & $7.37 \pm 1.19$ & $6.98 \pm 0.39$ & $15.83 \pm 1.80$ & $14.69 \pm 0.70$ & $14.81 \pm 0.98$ \\
\hline$R_{\text {opt }}\left(R_{\odot}\right)$ & $15.07 \pm 1.26$ & $16.41 \pm 0.72$ & $18.46 \pm 0.77$ & $16.09 \pm 0.65$ & $16.17 \pm 0.68$ \\
\hline$R_{\text {dist }}\left(R_{\odot}\right)$ & $16.42 \pm 0.84$ & $16.42 \pm 0.84$ & $16.42 \pm 0.84$ & $16.42 \pm 0.84$ & $16.50 \pm 0.84$ \\
\hline $\log g\left(\mathrm{~cm} \mathrm{~s}^{-2}\right)$ & $3.394 \pm 0.016$ & $3.427 \pm 0.008$ & $3.306 \pm 0.018$ & $3.302 \pm 0.012$ & $3.303 \pm 0.018$ \\
\hline$V_{\mathrm{rot}} \sin i\left(\mathrm{~km} \mathrm{~s}^{-1}\right)$ & $106.52 \pm 6.39$ & $92.57 \pm 5.59$ & $79.91 \pm 4.79$ & $92.99 \pm 5.89$ & $92.99 \pm 4.62$ \\
\hline$\chi_{U}^{2}$ & 26.11 & 24.74 & 21.14 & 17.76 & $\ldots$ \\
\hline$\chi_{B}^{2}$ & 46.71 & 43.57 & 24.96 & 19.33 & $\ldots$ \\
\hline$\chi_{V}^{2}$ & 34.81 & 32.49 & 24.58 & 23.99 & $\ldots$ \\
\hline$\chi_{\mathrm{RV}}^{2}$ & 554.13 & 551.57 & 531.83 & 536.32 & $\cdots$ \\
\hline$\chi_{\text {tot }}^{2}$ & 668.03 & 652.54 & 614.769 & 597.67 & $\ldots$ \\
\hline d.o.f. & 584 & 583 & 582 & 581 & $\ldots$ \\
\hline
\end{tabular}

Notes. The assumed stellar temperature is $T_{\text {eff }}=31,000 \mathrm{~K} . R_{\mathrm{opt}}$ is the stellar radius derived from the models. $R_{\text {dist }}$ is the stellar radius derived from the measured parallax and assumed temperature. $V_{\text {rot }} \sin i=95 \pm 6 \mathrm{~km} \mathrm{~s}^{-1}$ is the projected rotational velocity of the O-star derived from the models. Model A assumes a circular orbit and synchronous rotation. Model B assumes a circular orbit and nonsynchronous rotation. Model C assumes an eccentric orbit and pseudosynchronous rotation. Model D assumes an eccentric orbit and nonsynchronous rotation. The adopted parameters are the weighted averages of the values for Model $\mathrm{D}$ derived for each temperature in the range of $30,000 \mathrm{~K} \leqslant T_{\text {eff }} \leqslant 32,000 \mathrm{~K}$.

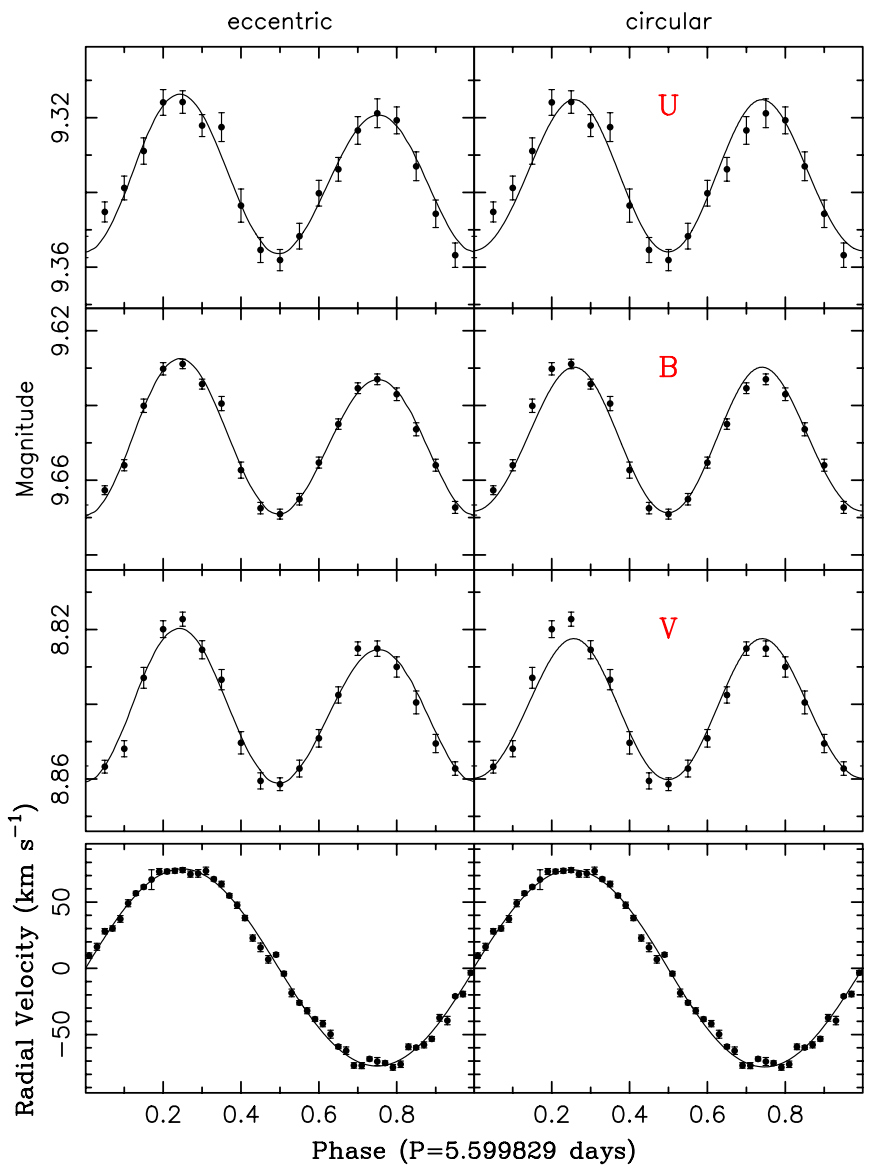

Figure 2. Top: the optical light curves and best-fitting models assuming an eccentric orbit with $e=0.018$ (Model $\mathrm{D}$, left panels) and a circular orbit (Model A, right panels). Note how much better the unequal maxima of the light curves are accommodated by the model that includes eccentricity. Bottom: the radial velocity measurements binned into 50 bins (filled circles) and the best-fitting model for the eccentric orbit (left) and the circular orbit (right).

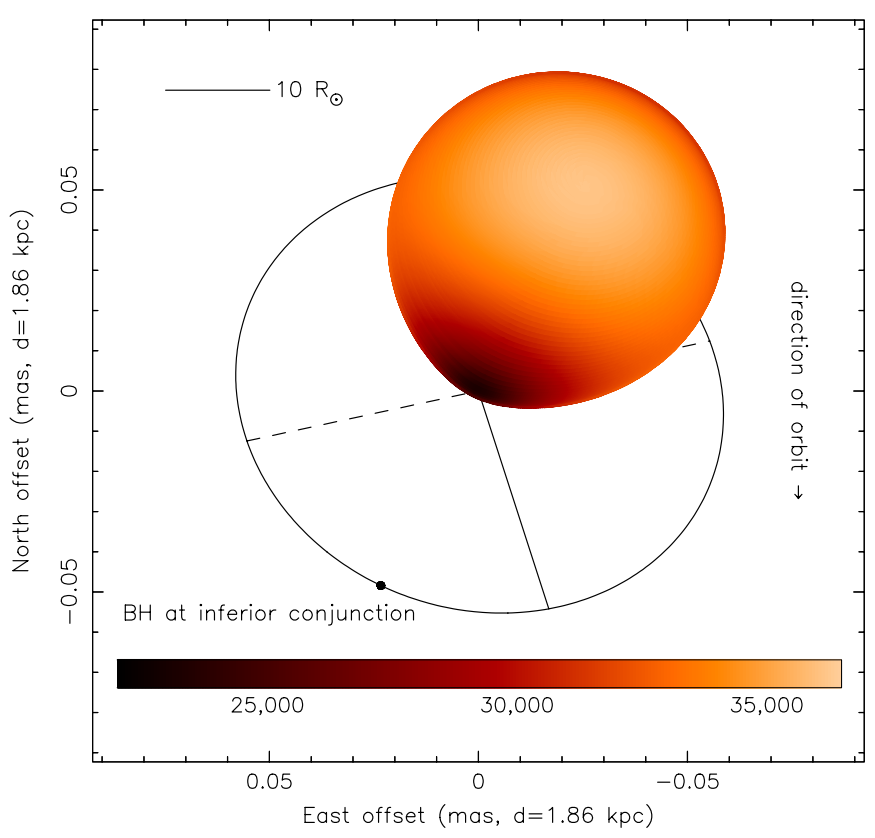

Figure 3. Schematic diagram of Cygnus $X-1$, shown as it would appear on the sky plane. The offsets are in milliarcseconds (mas), assuming a distance of $1.86 \mathrm{kpc}$. The orbital phase is $\phi=0.5$, which corresponds to the superior conjunction of the O-star. The orbit of the black hole is indicated by the ellipse, where the major and minor axes have been drawn in for clarity (solid line and dashed line, respectively). The direction of the orbital motion is clockwise, as determined by the radio observations (Reid et al. 2011). The color map represents the local effective temperature. The star is much cooler near the inner Lagrangian point because of the well-known effect of "gravity darkening" (Orosz \& Hauschildt 2000). The temperatures referred to in the main text, Figure 1 and Table 1 refer to intensity-weighted average values.

(A color version of this figure is available in the online journal.)

of the recent work considers circular orbits and synchronous rotation (e.g., Caballero-Nieves et al. 2009). While the eccentricity we find is small $(e=0.018 \pm 0.002$ for Model $\mathrm{D}$ at $T_{\text {eff }}=31,000 \mathrm{~K}$ ), it is highly significant. Allowing the orbit 
Table 2

Cygnus X-1 Final Parameters

\begin{tabular}{lc}
\hline \hline Parameter & Value \\
\hline$i(\mathrm{deg})$ & $27.06 \pm 0.76$ \\
$\Omega$ & $1.400 \pm 0.084$ \\
$e$ & $0.018 \pm 0.003$ \\
$\omega(\mathrm{deg})$ & $307.6 \pm 5.3$ \\
$M_{\mathrm{opt}}\left(M_{\odot}\right)$ & $19.16 \pm 1.90$ \\
$R_{\mathrm{opt}}\left(R_{\odot}\right)$ & $16.17 \pm 0.68$ \\
$\log g(\mathrm{cgs})$ & $3.303 \pm 0.018$ \\
$M\left(M_{\odot}\right)$ & $14.81 \pm 0.98$ \\
\hline
\end{tabular}

to be eccentric results in an improvement to the $\chi^{2}$ values of all three light curves and the radial velocity curve as well. As a separate check on our results, we fitted the light curves and the velocity curve separately and found the best-fitting values of $e$ and $\omega$ for each. For the light curves, which are derived from a homogeneous data set containing more than 800 observations spanning 27 years, we find $e=0.0249 \pm 0.003$ and $\omega=305 \pm 7^{\circ}$. For the velocity curve, we find $e=0.028 \pm 0.006$ and $\omega=307 \pm 13^{\circ}$. In addition to the remarkable consistency of the results, note that the argument of periastron we find is not consistent with either $90^{\circ}$ or $270^{\circ}$, which indicates that the eccentricity is not an artifact of tidal distortions (Wilson \& Sofia 1976; Eaton 2008).

\subsubsection{Sensitivity of the Results on the Model Assumptions}

A glance at Table 1 shows that some of the parameters, such as the inclination, seem to change considerably among the four models. These differences can be explained in part by how much weight one places on the external constraints, namely the radius found from the parallax distance and the observed rotational velocity. If we assume synchronous rotation, then the observed radius of $16.42 \pm 0.84 R_{\odot}$ (for $T_{\text {eff }}=31,000$ ) and the projected rotational velocity of $V_{\text {rot }} \sin i=96 \pm 6 \mathrm{~km} \mathrm{~s}^{-1}$ give an inclination of $i=39.8 \pm 3.9$. We ran a Model $\mathrm{C}^{\prime}$ that is identical to Model $\mathrm{C}$ except we fixed the errors on the external constraints to be a factor of 10 smaller (e.g., $16.42 \pm 0.084 R_{\odot}$ and $\left.V_{\text {rot }} \sin i=96 \pm 0.6 \mathrm{~km} \mathrm{~s}^{-1}\right)$. We found an inclination of $i=39.6 \pm 0.4$, which is consistent with the expected value. However, the fits are much worse, with $\chi^{2}=629.4$ compared to $\chi^{2}=614.8$. Likewise, we ran a Model $\mathrm{A}^{\prime}$ that is identical to Model A except for the use of the same hard external constraints, and we similarly found $i=39.6 \pm 0.4$ and $\chi^{2}=673.2$. Thus, in this limiting case where the radius and rotational velocity are forced to their observed values, the inclination is determined by these quantities and does not depend on the eccentricity.

In principle, the light curves should be sensitive to nonsynchronous rotation since the potential includes a term containing a factor of $\Omega^{2}$, where $\Omega$ is the ratio of the stellar rotational frequency to the orbital frequency (Orosz \& Hauschildt 2000). As shown in Table 1, we obtain improved fits to the light curve when the rotation is allowed to be nonsynchronous: Model B has a smaller $\chi^{2}$ than Model A (although both of these models are rejected since the eccentricity is nonzero), and Model D has a smaller $\chi^{2}$ than Model C. In the case of Model D, note that the values of $\chi^{2}$ for each of the $U, B$, and $V$ light curves have decreased relative to the values for Model $C$. When the rotation of the $\mathrm{O}$-star is not synchronous, the mapping between the radius, the inclination, and the observed projected rotational velocity is of course altered. Thus in Model D we are able to satisfy the constraints imposed both by the observed radius and the observed rotational velocity while providing optimal fits to the individual light curves.

Finally, we note that it is possible to achieve optimal fits to the light curves for an eccentric orbit and synchronous rotation if we ignore the constraints provided by the measured values of the radius and rotational velocity. However, without these constraints there are degeneracies among solutions. For example, two solutions with similar $\chi^{2}$ values exist: one solution has $i=21.4, R_{2}=22.98 R_{\odot}, V_{\text {rot }} \sin i=98.4 \mathrm{~km} \mathrm{~s}^{-1}$, and $\chi^{2}=597.0$, whereas another solution has $i=25.4$, $R_{2}=16.2 R_{\odot}, V_{\text {rot }} \sin i=63.0 \mathrm{~km} \mathrm{~s}^{-1}$, and $\chi^{2}=596.5$. In the former case, the derived rotational velocity is consistent with the observed value, but the derived stellar radius is much too large. In the latter case, the derived stellar radius is consistent with the radius computed from the parallax distance; however, the derived rotational velocity is much too small. As mentioned above, allowing the stellar rotation to be nonsynchronous allows us to satisfy all of the constraints while optimally fitting the light curves.

\section{DISCUSSION AND SUMMARY}

We find masses of $M_{\mathrm{opt}}=19.16 \pm 1.90 M_{\odot}$ and $M=$ $14.81 \pm 0.98 M_{\odot}$ for the O-star and black hole, respectively. These estimates are considerably more direct and robust than previous ones, owing largely to the new parallax distance. This secure trigonometric distance was used to derive a radius for the $\mathrm{O}$-star using the observed $K$-band magnitude to minimize uncertainties due to extinction and metallicity. The derived $\mathrm{O}$-star radius strongly constrains the dynamical model. In addition, we have also used the observed rotational velocity of the $\mathrm{O}$-star as an observational constraint and sought models that simultaneously satisfy all of the constraints. We have explored possible sources of systematic error by considering a wide range of possible temperatures for the companion $\mathrm{O}$-star and circular and eccentric models separately. The optical light curves we used come from a long-term program which used the same instrumentation and should represent the mean state of the system quite well. Overall, the uncertainties in the dynamical model are as about as small as they can be in a noneclipsing system.

By way of comparison with previous work, a recent summary of mass estimates is given in Caballero-Nieves et al. (2009). The four estimates given for the black hole mass that are based on dynamical studies (see Section 1) are quite uncertain and generally consistent with our result. Other estimates, which are based on less certain methods, generally imply a lower mass, $M \approx 10 M_{\odot}$. For example, Abubekerov et al. (2005) reported a mass in the range $8.2 \leqslant M \leqslant 12.8 M_{\odot}$ from their analysis of optical spectral line profiles. Shaposhnikov \& Titarchuk (2007) found a mass in the range $7.9 \leqslant M \leqslant 9.5 M_{\odot}$ using X-ray spectral/timing data and a scaling relation based on the dynamically determined masses of three black holes. Such methods, while intriguing, are not well established and are prone to large systematic errors compared to the time-tested and straightforward approach that we have taken.

Our improved dynamical model for Cyg X-1 enables other studies of this key black hole binary. Using our precise measurement of the distance (Reid et al. 2011), we are now able to compute the stellar luminosity as a function of the assumed temperature, which allows one to place the star on an H-R diagram with some confidence. We have also provided precise values of the component masses, the eccentricity, and the degree of nonsynchronous rotation, quantities which may be used to test binary evolutionary models (such a study will be presented else- 


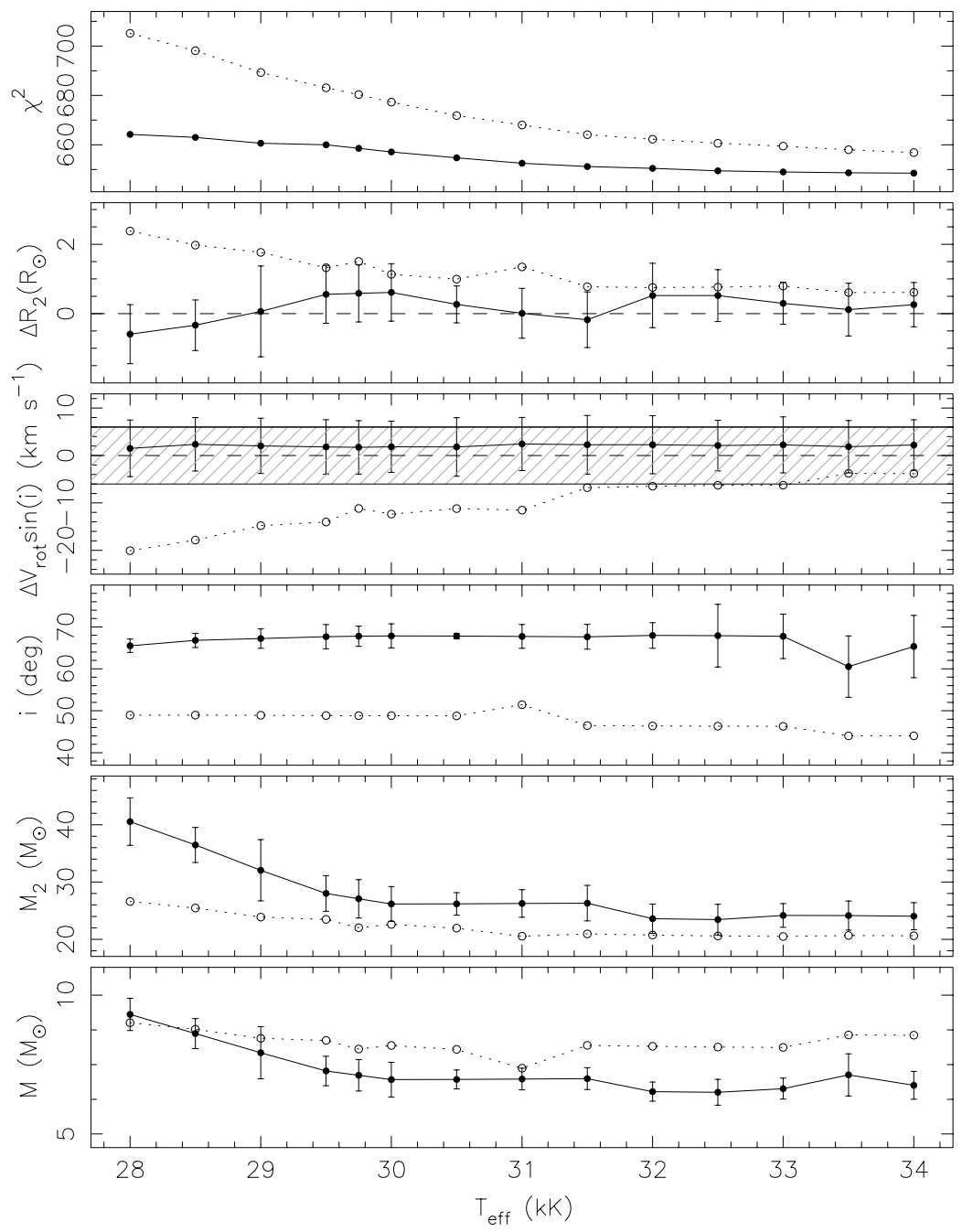

Figure 4. Results of the dynamical modeling assuming a circular orbit. Various quantities are plotted as a function of temperature for the model assuming synchronous rotation (open circles) and nonsynchronous rotation (filled circles). From top to bottom the plots show (a) the total $\chi^{2}$, (b) the difference between $R_{\text {dist }}$ and $R_{2}$ in solar radii, (c) the difference between the observed projected rotational velocity and the value derived from the models in $\mathrm{km} \mathrm{s}^{-1}$ where the hatched region denotes the $1 \sigma$ uncertainty on the measured value, (d) the inclination in degrees, (e) the mass of the O-star in solar masses, and (f) the mass of the black hole in solar masses. In general, for the synchronous models the O-star radius derived from the models is smaller than the radius derived from the distance whereas the derived projected rotational velocity is larger than observed.

where). Finally, with our accurate values for the distance, the black hole mass, and the orbital inclination angle, one can model $\mathrm{X}$-ray spectra of the source in order to measure the spin of the black hole primary. In our third paper in this series, Gou et al. (2011), we show that Cyg X-1 is a near-extreme Kerr black hole.

We thank Catherine Brocksopp for sending us the optical light curves. The work of J.E.M. was supported in part by NASA grant NNX11AD08G. This research has made use of NASA's Astrophysics Data System.

\section{APPENDIX}

\section{ELC FITTING DETAILS}

We computed models for 14 values of $T_{\text {eff }}$ between 28,000 and $34,000 \mathrm{~K}$. We fit for each temperature separately since the derived radius from the parallax distance depends on the temperature and the derived radius is used as an external constraint. For each model at each temperature, ELC's genetic code was run twice using different initial populations and the
Monte Carlo Markov Chain code was run once. The best solutions were then refined using a simple grid search. We computed uncertainties on the fitted parameters and on the derived parameters (e.g., the black hole mass, $M$, the gravity of the O-star, $\log g$, etc.) using the procedure discussed in Orosz et al. (2002). The results for all 14 temperatures are shown in Table 3 and Figures 4 and 5. As discussed in the main text, the improvement in the $\chi^{2}$ values as one goes from Model A to Model D is evident. For Model A, we consistently find $R_{\text {opt }}<R_{\text {dist }}$. Furthermore, the rotational velocity derived from the model is consistently larger than the observed value. By allowing nonsynchronous rotation for the circular orbit (as in Model B), the model-derived stellar radius agrees with the radius computed from the distance, and the model-derived rotational velocity agrees with the measured one. Generally speaking, the star rotates slower than its synchronous value. However, an inspection of the light curves (see Figure 2 in the main text) shows that the maximum near phase 0.25 is slightly higher than the maximum near 0.75 . Because an ellipsoidal model predicts maxima of equal intensity, the fit to the data is not optimal. We accommodate the unequal maxima by adding eccentricity to the 
Table 3

Cygnus X-1 Model Parameters

\begin{tabular}{|c|c|c|c|c|c|c|c|c|c|c|c|c|c|c|c|c|}
\hline $\begin{array}{l}T_{\text {eff }} \\
(\mathrm{K})\end{array}$ & Model & $\begin{array}{c}i \\
(\mathrm{deg})\end{array}$ & $\Omega$ & $e$ & $\begin{array}{c}\omega \\
(\mathrm{deg})\end{array}$ & $\begin{array}{l}M_{\mathrm{opt}} \\
\left(M_{\odot}\right)\end{array}$ & $\begin{array}{c}M \\
\left(M_{\odot}\right)\end{array}$ & $\begin{array}{l}R_{\mathrm{opt}}{ }^{\mathrm{a}} \\
\left(R_{\odot}\right)\end{array}$ & $\begin{array}{l}R_{\text {dist }} \mathrm{b} \\
\left(R_{\odot}\right)\end{array}$ & $\begin{array}{l}\log g \\
(\mathrm{cgs})\end{array}$ & $\begin{array}{l}V_{\text {rot }} \sin i^{\mathrm{c}} \\
\left(\mathrm{km} \mathrm{s}^{-1}\right)\end{array}$ & $\chi_{U}^{2}$ & $\chi_{B}^{2}$ & $\chi_{V}^{2}$ & $\chi_{\mathrm{RV}}^{2}$ & $\chi_{\text {tot }}^{2}$ \\
\hline 28000 & $\mathrm{~A}^{\mathrm{d}}$ & $\begin{array}{r}48.96 \\
\pm 2.58\end{array}$ & 1.000 & $\ldots$ & $\ldots$ & $\begin{array}{r}26.61 \\
\pm 2.81\end{array}$ & $\begin{array}{r}9.01 \\
\pm 0.98\end{array}$ & $\begin{array}{r}16.88 \\
\pm 0.82\end{array}$ & $\begin{array}{r}19.26 \\
\pm 0.98\end{array}$ & $\begin{array}{r}3.408 \\
\pm 0.009\end{array}$ & $\begin{array}{r}115.08 \\
\pm 4.05\end{array}$ & 31.13 & 59.68 & 41.26 & 556.00 & 705.14 \\
\hline 28000 & $\mathrm{~B}^{\mathrm{e}}$ & $\begin{array}{r}65.50 \\
\pm 1.59\end{array}$ & $\begin{array}{r}0.573 \\
\pm 0.039\end{array}$ & $\cdots$ & $\ldots$ & $\begin{array}{r}40.56 \\
\pm 4.14\end{array}$ & $\begin{array}{r}9.31 \\
\pm 0.58\end{array}$ & $\begin{array}{r}19.85 \\
\pm 0.85\end{array}$ & $\begin{array}{r}19.26 \\
\pm 0.98\end{array}$ & $\begin{array}{r}3.450 \\
\pm 0.008\end{array}$ & $\begin{array}{r}93.49 \\
\pm 5.97\end{array}$ & 27.53 & 49.29 & 35.33 & 551.63 & 664.20 \\
\hline 28000 & $C^{f}$ & $\begin{array}{r}26.79 \\
\pm 0.34\end{array}$ & 1.000 & $\begin{array}{r}0.022 \\
\pm 0.002\end{array}$ & $\begin{array}{r}296.4 \\
\pm 3.6\end{array}$ & $\begin{array}{r}31.59 \\
\pm 3.93\end{array}$ & $\begin{array}{r}19.58 \\
\pm 1.26\end{array}$ & $\begin{array}{r}20.33 \\
\pm 0.98\end{array}$ & $\begin{array}{r}19.26 \\
\pm 0.98\end{array}$ & $\begin{array}{r}3.321 \\
\pm 0.015\end{array}$ & $\begin{array}{r}86.79 \\
\pm 4.87\end{array}$ & 18.85 & 23.13 & 28.37 & 533.37 & 606.77 \\
\hline 28000 & $D^{g}$ & $\begin{array}{r}27.17 \\
\pm 0.33 \\
\end{array}$ & $\begin{array}{r}1.187 \\
\pm 0.116 \\
\end{array}$ & $\begin{array}{r}0.021 \\
\pm 0.002 \\
\end{array}$ & $\begin{array}{r}298.1 \\
\pm 3.9 \\
\end{array}$ & $\begin{array}{r}28.76 \\
\pm 3.74 \\
\end{array}$ & $\begin{array}{r}18.31 \\
\pm 1.37 \\
\end{array}$ & $\begin{array}{r}19.30 \\
\pm 1.24 \\
\end{array}$ & $\begin{array}{r}19.26 \\
\pm 0.98 \\
\end{array}$ & $\begin{array}{r}3.325 \\
\pm 0.012 \\
\end{array}$ & $\begin{array}{r}94.80 \\
\pm 5.28 \\
\end{array}$ & 18.94 & 22.83 & 27.43 & 534.25 & 603.45 \\
\hline 28500 & A & $\begin{array}{r}48.96 \\
\pm 2.55\end{array}$ & 1.000 & $\ldots$ & $\ldots$ & $\begin{array}{r}25.45 \\
\pm 2.25\end{array}$ & $\begin{array}{r}8.77 \\
\pm 0.74\end{array}$ & $\begin{array}{r}16.55 \\
\pm 0.59\end{array}$ & $\begin{array}{r}18.53 \\
\pm 0.95\end{array}$ & $\begin{array}{r}3.406 \\
\pm 0.009\end{array}$ & $\begin{array}{r}112.83 \\
\pm 4.20\end{array}$ & 30.69 & 58.09 & 40.45 & 555.65 & 698.08 \\
\hline 28500 & B & $\begin{array}{r}66.79 \\
\pm 1.69\end{array}$ & $\begin{array}{r}0.591 \\
\pm 0.041\end{array}$ & $\ldots$ & $\ldots$ & $\begin{array}{r}36.48 \\
\pm 3.07\end{array}$ & $\begin{array}{r}8.62 \\
\pm 0.54\end{array}$ & $\begin{array}{r}18.87 \\
\pm 0.73\end{array}$ & $\begin{array}{r}18.53 \\
\pm 0.95\end{array}$ & $\begin{array}{r}3.448 \\
\pm 0.008\end{array}$ & $\begin{array}{r}92.64 \\
\pm 5.64\end{array}$ & 27.13 & 48.42 & 35.25 & 551.91 & 662.98 \\
\hline 28500 & $\mathrm{C}$ & $\begin{array}{r}26.66 \\
\pm 0.25\end{array}$ & 1.000 & $\begin{array}{r}0.022 \\
\pm 0.002\end{array}$ & $\begin{array}{r}296.4 \\
\pm 4.1\end{array}$ & $\begin{array}{r}29.36 \\
\pm 2.98\end{array}$ & $\begin{array}{r}18.89 \\
\pm 1.11\end{array}$ & $\begin{array}{r}19.77 \\
\pm 0.73\end{array}$ & $\begin{array}{r}18.53 \\
\pm 0.95\end{array}$ & $\begin{array}{r}3.314 \\
\pm 0.010\end{array}$ & $\begin{array}{r}84.02 \\
\pm 3.13\end{array}$ & 18.81 & 23.04 & 27.89 & 533.17 & 607.90 \\
\hline 28500 & $\mathrm{D}$ & $\begin{array}{r}27.14 \\
\pm 0.28 \\
\end{array}$ & $\begin{array}{r}1.263 \\
\pm 0.112 \\
\end{array}$ & $\begin{array}{r}0.020 \\
\pm 0.002 \\
\end{array}$ & $\begin{array}{r}299.6 \\
\pm 4.6 \\
\end{array}$ & $\begin{array}{r}25.18 \\
\pm 3.40 \\
\end{array}$ & $\begin{array}{r}17.04 \\
\pm 1.27 \\
\end{array}$ & $\begin{array}{r}18.19 \\
\pm 1.06 \\
\end{array}$ & $\begin{array}{r}18.53 \\
\pm 0.95 \\
\end{array}$ & $\begin{array}{r}3.319 \\
\pm 0.010 \\
\end{array}$ & $\begin{array}{r}94.96 \\
\pm 5.28 \\
\end{array}$ & 18.75 & 22.29 & 26.76 & 534.55 & 602.38 \\
\hline 29000 & A & $\begin{array}{r}48.91 \\
\pm 2.45\end{array}$ & 1.000 & $\ldots$ & $\ldots$ & $\begin{array}{r}23.88 \\
\pm 1.83\end{array}$ & $\begin{array}{r}8.45 \\
\pm 0.78\end{array}$ & $\begin{array}{r}16.12 \\
\pm 0.64\end{array}$ & $\begin{array}{r}17.88 \\
\pm 0.99\end{array}$ & $\begin{array}{r}3.401 \\
\pm 0.010\end{array}$ & $\begin{array}{r}109.80 \\
\pm 3.97\end{array}$ & 29.77 & 5.81 & 39.34 & 555.14 & 589.30 \\
\hline 29000 & B & $\begin{array}{r}67.21 \\
\pm 2.30\end{array}$ & $\begin{array}{r}0.626 \\
\pm 0.053\end{array}$ & $\ldots$ & $\ldots$ & $\begin{array}{r}32.06 \\
\pm 5.35\end{array}$ & $\begin{array}{r}7.93 \\
\pm 0.94\end{array}$ & $\begin{array}{r}17.82 \\
\pm 1.31\end{array}$ & $\begin{array}{r}17.88 \\
\pm 0.99\end{array}$ & $\begin{array}{r}3.442 \\
\pm 0.009\end{array}$ & $\begin{array}{r}92.97 \\
\pm 5.83\end{array}$ & 26.76 & 47.33 & 34.66 & 551.77 & 660.64 \\
\hline 29000 & $\mathrm{C}$ & $\begin{array}{r}26.59 \\
\pm 0.31\end{array}$ & 1.000 & $\begin{array}{r}0.022 \\
\pm 0.002\end{array}$ & $\begin{array}{r}297.0 \\
\pm 5.0\end{array}$ & $\begin{array}{r}28.37 \\
\pm 2.40\end{array}$ & $\begin{array}{r}18.60 \\
\pm 0.81\end{array}$ & $\begin{array}{r}19.52 \\
\pm 0.63\end{array}$ & $\begin{array}{r}17.88 \\
\pm 0.99\end{array}$ & $\begin{array}{r}3.310 \\
\pm 0.010\end{array}$ & $\begin{array}{r}82.70 \\
\pm 2.74\end{array}$ & 18.64 & 22.72 & 27.48 & 33.05 & 508.72 \\
\hline 29000 & $\mathrm{D}$ & $\begin{array}{r}27.13 \\
\pm 0.35 \\
\end{array}$ & $\begin{array}{r}1.330 \\
\pm 0.110 \\
\end{array}$ & $\begin{array}{r}0.020 \\
\pm 0.002 \\
\end{array}$ & $\begin{array}{r}301.5 \\
\pm 5.2 \\
\end{array}$ & $\begin{array}{r}22.28 \\
\pm 2.84 \\
\end{array}$ & $\begin{array}{r}15.95 \\
\pm 1.15 \\
\end{array}$ & $\begin{array}{r}17.24 \\
\pm 0.96 \\
\end{array}$ & $\begin{array}{r}17.88 \\
\pm 0.99 \\
\end{array}$ & $\begin{array}{r}3.313 \\
\pm 0.010 \\
\end{array}$ & $\begin{array}{r}94.70 \\
\pm 4.97 \\
\end{array}$ & 18.30 & 21.18 & 25.67 & 535.31 & 601.21 \\
\hline 29500 & A & $\begin{array}{r}48.85 \\
\pm 2.45\end{array}$ & 1.000 & $\ldots$ & $\ldots$ & $\begin{array}{r}23.48 \\
\pm 2.19\end{array}$ & $\begin{array}{r}8.37 \\
\pm 0.60\end{array}$ & $\begin{array}{r}16.02 \\
\pm 0.49\end{array}$ & & $\begin{array}{r}3.399 \\
\pm 0.012\end{array}$ & & 28.89 & 53.39 & 38.06 & 555.08 & 683.10 \\
\hline 29500 & B & $\begin{array}{r}67.66 \\
\pm 2.88\end{array}$ & $\begin{array}{r}0.664 \\
\pm 0.040\end{array}$ & $\ldots$ & $\ldots$ & $\begin{array}{r}28.02 \\
\pm 3.12\end{array}$ & $\begin{array}{r}7.27 \\
\pm 0.53\end{array}$ & $\begin{array}{r}16.79 \\
\pm 0.83\end{array}$ & $\begin{array}{r}17.34 \\
\pm 0.89\end{array}$ & $\begin{array}{r}3.435 \\
\pm 0.006\end{array}$ & $\begin{array}{r}93.19 \\
\pm 5.74\end{array}$ & 26.61 & 46.69 & 34.43 & 551.80 & 660.02 \\
\hline 29500 & $\mathrm{C}$ & $\begin{array}{r}29.00 \\
\pm 0.40\end{array}$ & 1.000 & $\begin{array}{r}0.028 \\
\pm 0.002\end{array}$ & $\begin{array}{r}300.7 \\
\pm 4.1\end{array}$ & $\begin{array}{r}25.80 \\
\pm 0.62\end{array}$ & $\begin{array}{r}15.72 \\
\pm 0.32\end{array}$ & $\begin{array}{r}18.45 \\
\pm 0.17\end{array}$ & $\begin{array}{r}17.34 \\
\pm 0.89\end{array}$ & $\begin{array}{r}3.317 \\
\pm 0.005\end{array}$ & & 22.03 & 27.08 & 26.37 & 532.01 & 611.39 \\
\hline 29500 & D & $\begin{array}{r}27.13 \\
\pm 0.33 \\
\end{array}$ & $\begin{array}{r}1.347 \\
\pm 0.063 \\
\end{array}$ & $\begin{array}{r}0.019 \\
\pm 0.002 \\
\end{array}$ & $\begin{array}{c}302.4 \\
\pm 9.99 \\
\end{array}$ & $\begin{array}{r}21.32 \\
\pm 1.73 \\
\end{array}$ & $\begin{array}{r}15.57 \\
\pm 0.79 \\
\end{array}$ & $\begin{array}{r}16.92 \\
\pm 0.63 \\
\end{array}$ & $\begin{array}{r}17.34 \\
\pm 0.89 \\
\end{array}$ & $\begin{array}{r}3.310 \\
\pm 0.011 \\
\end{array}$ & $\begin{array}{r}94.20 \\
\pm 4.70 \\
\end{array}$ & 18.18 & 20.80 & 25.37 & 535.26 & 599.84 \\
\hline 29750 & $A$ & $\begin{array}{r}48.82 \\
\pm 5.14\end{array}$ & 1.000 & $\ldots$ & $\ldots$ & $\begin{array}{r}22.03 \\
\pm 2.25\end{array}$ & $\begin{array}{r}8.06 \\
\pm 0.97\end{array}$ & $\begin{array}{r}15.61 \\
\pm 0.73\end{array}$ & $\begin{array}{r}17.11 \\
\pm 0.88\end{array}$ & $\begin{array}{r}3.394 \\
\pm 0.019\end{array}$ & $\begin{array}{r}106.17 \\
\pm 7.00\end{array}$ & 28.71 & 52.94 & 37.68 & 554.57 & 680.32 \\
\hline 29750 & B & $\begin{array}{r}67.78 \\
\pm 2.40\end{array}$ & $\begin{array}{r}0.675 \\
\pm 0.055\end{array}$ & $\cdots$ & $\ldots$ & $\begin{array}{r}27.08 \\
\pm 3.35\end{array}$ & $\begin{array}{r}7.11 \\
\pm 0.57\end{array}$ & $\begin{array}{r}16.53 \\
\pm 0.83\end{array}$ & $\begin{array}{r}17.11 \\
\pm 0.88\end{array}$ & $\begin{array}{r}3.434 \\
\pm 0.011\end{array}$ & $\begin{array}{r}93.29 \\
\pm 5.63\end{array}$ & 26.06 & 45.74 & 34.43 & 51.80 & 658.56 \\
\hline 29750 & $\mathrm{C}$ & $\begin{array}{r}28.93 \\
\pm 2.83\end{array}$ & 1.000 & $\begin{array}{r}0.027 \\
\pm 0.007\end{array}$ & $\begin{array}{r}301.5 \\
\pm 8.3\end{array}$ & $\begin{array}{r}25.45 \\
\pm 2.72\end{array}$ & $\begin{array}{r}15.65 \\
\pm 2.91\end{array}$ & $\begin{array}{r}18.38 \\
\pm 1.09\end{array}$ & $\begin{array}{r}17.11 \\
\pm 0.88\end{array}$ & $\begin{array}{r}3.315 \\
\pm 0.025\end{array}$ & $\begin{array}{r}85.26 \\
\pm 9.45\end{array}$ & 26.24 & 26.82 & 25.83 & 531.92 & 611.22 \\
\hline 29750 & D & $\begin{array}{r}27.09 \\
\pm 0.32 \\
\end{array}$ & $\begin{array}{r}1.358 \\
\pm 0.080 \\
\end{array}$ & $\begin{array}{r}0.019 \\
\pm 0.002 \\
\end{array}$ & $\begin{array}{r}303.4 \\
\pm 5.1 \\
\end{array}$ & $\begin{array}{r}20.66 \\
\pm 2.76 \\
\end{array}$ & $\begin{array}{r}15.34 \\
\pm 1.08 \\
\end{array}$ & $\begin{array}{r}16.71 \\
\pm 0.92 \\
\end{array}$ & $\begin{array}{r}17.11 \\
\pm 0.88 \\
\end{array}$ & $\begin{array}{r}3.307 \\
\pm 0.011 \\
\end{array}$ & $\begin{array}{r}93.56 \\
\pm 4.88 \\
\end{array}$ & 18.00 & 20.13 & 24.75 & 535.50 & 598.65 \\
\hline 00 & $A$ & $\begin{array}{r}48.82 \\
\pm 3.07\end{array}$ & & & 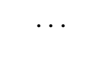 & $\begin{array}{r}22.61 \\
\pm 1.81\end{array}$ & $\begin{array}{r}8.19 \\
\pm 0.78\end{array}$ & $\begin{array}{r}15.78 \\
\pm 0.64\end{array}$ & $\begin{array}{r}16.91 \\
\pm 0.86\end{array}$ & $\begin{array}{r}3.396 \\
\pm 0.012\end{array}$ & $\begin{array}{l}107 \\
\pm 5\end{array}$ & 3.06 & 1.49 & 37.01 & 54.77 & 677.29 \\
\hline 30000 & B & $\begin{array}{r}67.86 \\
\pm 2.87\end{array}$ & $\begin{array}{r}0.683 \\
\pm 0.045\end{array}$ & $\ldots$ & $\ldots$ & $\begin{array}{r}26.16 \\
\pm 3.04\end{array}$ & $\begin{array}{r}6.96 \\
\pm 0.63\end{array}$ & $\begin{array}{r}16.30 \\
\pm 0.83\end{array}$ & $\begin{array}{r}16.91 \\
\pm 0.86\end{array}$ & $\begin{array}{r}3.431 \\
\pm 0.008\end{array}$ & $\begin{array}{r}93.17 \\
\pm 5.39\end{array}$ & 25.81 & 45.18 & 33.70 & 551.81 & 657.10 \\
\hline 30000 & $\mathrm{C}$ & $\begin{array}{r}28.90 \\
\pm 0.32\end{array}$ & 1.000 & $\begin{array}{r}0.027 \\
\pm 0.006\end{array}$ & $\begin{array}{r}302.4 \\
\pm 4.2\end{array}$ & $\begin{array}{r}25.57 \\
\pm 2.34\end{array}$ & $\begin{array}{r}15.71 \\
\pm 1.19\end{array}$ & $\begin{array}{r}18.42 \\
\pm 0.53\end{array}$ & $\begin{array}{r}16.91 \\
\pm 0.86\end{array}$ & $\begin{array}{r}3.315 \\
\pm 0.027\end{array}$ & $\begin{array}{r}85.33 \\
\pm 9.52\end{array}$ & 8.33 & 26.29 & .33 & 31.90 & 510.91 \\
\hline 30000 & D & $\begin{array}{r}27.11 \\
\pm 0.37 \\
\end{array}$ & $\begin{array}{r}1.376 \\
\pm 0.094 \\
\end{array}$ & $\begin{array}{r}0.019 \\
\pm 0.002 \\
\end{array}$ & $\begin{array}{r}304.3 \\
\pm 4.8 \\
\end{array}$ & $\begin{array}{r}20.21 \\
\pm 1.80 \\
\end{array}$ & $\begin{array}{r}15.14 \\
\pm 0.78 \\
\end{array}$ & $\begin{array}{r}16.53 \\
\pm 0.64 \\
\end{array}$ & $\begin{array}{r}16.91 \\
\pm 0.86 \\
\end{array}$ & $\begin{array}{r}3.307 \\
\pm 0.011 \\
\end{array}$ & $\begin{array}{r}93.86 \\
\pm 5.17 \\
\end{array}$ & 17.98 & 20.19 & 24.89 & 535.63 & 598.92 \\
\hline 30500 & A & $\begin{array}{r}48.78 \\
\pm 2.77\end{array}$ & 1.000 & $\ldots$ & $\ldots$ & $\begin{array}{r}21.94 \\
\pm 2.17\end{array}$ & $\begin{array}{r}8.04 \\
\pm 0.85\end{array}$ & $\begin{array}{r}15.62 \\
\pm 0.75\end{array}$ & $\begin{array}{r}16.61 \\
\pm 0.85\end{array}$ & $\begin{array}{r}3.392 \\
\pm 0.015\end{array}$ & $\begin{array}{r}106.19 \\
\pm 5.44\end{array}$ & 27.18 & 49.42 & 35.84 & 554.54 & 671.84 \\
\hline 30500 & B & $\begin{array}{r}67.80 \\
\pm 0.67\end{array}$ & $\begin{array}{r}0.681 \\
\pm 0.040\end{array}$ & $\ldots$ & $\ldots$ & $\begin{array}{r}26.18 \\
\pm 1.96\end{array}$ & $\begin{array}{r}6.96 \\
\pm 0.34\end{array}$ & $\begin{array}{r}16.35 \\
\pm 0.53\end{array}$ & $\begin{array}{r}16.61 \\
\pm 0.85\end{array}$ & $\begin{array}{r}3.429 \\
\pm 0.007\end{array}$ & $\begin{array}{r}93.19 \\
\pm 6.17\end{array}$ & 25.29 & 44.34 & 33.15 & 551.76 & 654.73 \\
\hline 30500 & $\mathrm{C}$ & $\begin{array}{r}28.78 \\
\pm 0.36\end{array}$ & 1.000 & $\begin{array}{r}0.026 \\
\pm 0.002\end{array}$ & $\begin{array}{r}303.5 \\
\pm 4.9\end{array}$ & $\begin{array}{r}25.44 \\
\pm 1.98\end{array}$ & $\begin{array}{r}15.75 \\
\pm 0.32\end{array}$ & $\begin{array}{r}18.41 \\
\pm 0.09\end{array}$ & $\begin{array}{r}16.61 \\
\pm 0.85\end{array}$ & $\begin{array}{r}3.313 \\
\pm 0.005\end{array}$ & $\begin{array}{r}84.79 \\
\pm 1.03\end{array}$ & 18.20 & 25.31 & 24.71 & 531.95 & 610.76 \\
\hline 30500 & $\mathrm{D}$ & $\begin{array}{r}27.07 \\
\pm 0.29 \\
\end{array}$ & $\begin{array}{r}1.392 \\
\pm 0.071 \\
\end{array}$ & $\begin{array}{r}0.018 \\
\pm 0.003 \\
\end{array}$ & $\begin{array}{r}306.3 \\
\pm 5.3 \\
\end{array}$ & $\begin{array}{r}19.54 \\
\pm 1.96 \\
\end{array}$ & $\begin{array}{r}14.90 \\
\pm 0.71 \\
\end{array}$ & $\begin{array}{r}16.30 \\
\pm 0.71 \\
\end{array}$ & $\begin{array}{r}16.61 \\
\pm 0.85 \\
\end{array}$ & $\begin{array}{r}3.304 \\
\pm 0.013 \\
\end{array}$ & $\begin{array}{r}93.46 \\
\pm 4.15 \\
\end{array}$ & 17.84 & 19.71 & 24.41 & 536.01 & 598.17 \\
\hline 31000 & A & $\begin{array}{r}51.45 \\
\pm 7.46\end{array}$ & 1.000 & $\ldots$ & $\ldots$ & $\begin{array}{r}20.53 \\
\pm 2.00\end{array}$ & $\begin{array}{r}7.37 \\
\pm 1.19\end{array}$ & $\begin{array}{r}15.07 \\
\pm 1.26\end{array}$ & $\begin{array}{r}16.42 \\
\pm 0.84\end{array}$ & $\begin{array}{r}3.394 \\
\pm 0.016\end{array}$ & $\begin{array}{r}106.52 \\
\pm 6.39\end{array}$ & 6.11 & 46.71 & 34.81 & 554.13 & 668.03 \\
\hline 31000 & B & $\begin{array}{r}67.74 \\
\pm 2.83\end{array}$ & $\begin{array}{r}0.674 \\
\pm 0.043\end{array}$ & $\ldots$ & $\ldots$ & $\begin{array}{r}26.27 \\
\pm 2.41\end{array}$ & $\begin{array}{r}6.98 \\
\pm 0.39\end{array}$ & $\begin{array}{r}16.41 \\
\pm 0.72\end{array}$ & $\begin{array}{r}16.42 \\
\pm 0.84\end{array}$ & $\begin{array}{r}3.427 \\
\pm 0.008\end{array}$ & $\begin{array}{r}92.57 \\
\pm 5.59\end{array}$ & 24.74 & 43.57 & 32.49 & 551.57 & 652.54 \\
\hline 31000 & $\mathrm{C}$ & $\begin{array}{r}28.50 \\
\pm 2.21\end{array}$ & 1.000 & $\begin{array}{r}0.026 \\
\pm 0.003\end{array}$ & $\begin{array}{r}303.5 \\
\pm 5.1\end{array}$ & $\begin{array}{r}25.17 \\
\pm 2.54\end{array}$ & $\begin{array}{r}15.83 \\
\pm 1.80\end{array}$ & $\begin{array}{r}18.46 \\
\pm 0.77\end{array}$ & $\begin{array}{r}16.42 \\
\pm 0.84\end{array}$ & $\begin{array}{r}3.306 \\
\pm 0.018\end{array}$ & $\begin{array}{r}79.91 \\
\pm 4.79\end{array}$ & 21.14 & 24.96 & 24.58 & 531.83 & 614.77 \\
\hline
\end{tabular}


Table 3

(Continued)

\begin{tabular}{|c|c|c|c|c|c|c|c|c|c|c|c|c|c|c|c|c|}
\hline $\begin{array}{l}T_{\text {eff }} \\
(\mathrm{K})\end{array}$ & Model & $\begin{array}{c}i \\
(\mathrm{deg})\end{array}$ & $\Omega$ & $e$ & $\begin{array}{c}\omega \\
(\operatorname{deg})\end{array}$ & $\begin{array}{l}M_{\mathrm{opt}} \\
\left(M_{\odot}\right)\end{array}$ & $\begin{array}{c}M \\
\left(M_{\odot}\right)\end{array}$ & $\begin{array}{l}R_{\mathrm{opt}}{ }^{\mathrm{a}} \\
\left(R_{\odot}\right)\end{array}$ & $\begin{array}{l}R_{\text {dist }}{ }^{\mathrm{b}} \\
\left(R_{\odot}\right)\end{array}$ & $\begin{array}{l}\log g \\
(\mathrm{cgs})\end{array}$ & $\begin{array}{l}V_{\text {rot }} \sin i^{\mathrm{c}} \\
\left(\mathrm{km} \mathrm{s}^{-1}\right)\end{array}$ & $\chi_{U}^{2}$ & $\chi_{B}^{2}$ & $\chi_{V}^{2}$ & $\chi_{\mathrm{RV}}^{2}$ & $\chi_{\text {tot }}^{2}$ \\
\hline 31000 & D & $\begin{array}{r}27.03 \\
\pm 0.41\end{array}$ & $\begin{array}{r}1.404 \\
\pm 0.099\end{array}$ & $\begin{array}{r}0.018 \\
\pm 0.002\end{array}$ & $\begin{array}{r}308.1 \\
\pm 5.5\end{array}$ & $\begin{array}{r}18.97 \\
\pm 2.15\end{array}$ & $\begin{array}{r}14.69 \\
\pm 0.70\end{array}$ & $\begin{array}{r}16.09 \\
\pm 0.65\end{array}$ & $\begin{array}{r}16.42 \\
\pm 0.84\end{array}$ & $\begin{array}{r}3.302 \\
\pm 0.012\end{array}$ & $\begin{array}{r}92.99 \\
\pm 5.89\end{array}$ & 17.76 & 19.33 & 23.99 & 536.32 & 597.67 \\
\hline 31500 & A & $\begin{array}{r}46.47 \\
\pm 2.89\end{array}$ & 1.000 & & $\ldots$ & $\begin{array}{r}20.94 \\
\pm 2.29\end{array}$ & $\begin{array}{r}8.19 \\
\pm 0.77\end{array}$ & $\begin{array}{r}15.53 \\
\pm 0.71\end{array}$ & $\begin{array}{r}16.31 \\
\pm 0.83\end{array}$ & $\begin{array}{r}3.376 \\
\pm 0.016\end{array}$ & $\begin{array}{r}101.78 \\
\pm 5.21\end{array}$ & 26.11 & 47.59 & 34.20 & 554.08 & 664.12 \\
\hline 31500 & B & $\begin{array}{r}67.64 \\
\pm 2.95\end{array}$ & $\begin{array}{r}0.673 \\
\pm 0.045\end{array}$ & $\ldots$ & $\ldots$ & $\begin{array}{r}26.31 \\
\pm 3.10\end{array}$ & $\begin{array}{r}6.99 \\
\pm 0.39\end{array}$ & $\begin{array}{r}16.49 \\
\pm 0.80\end{array}$ & $\begin{array}{r}16.31 \\
\pm 0.83\end{array}$ & $\begin{array}{r}3.424 \\
\pm 0.011\end{array}$ & $\begin{array}{r}92.74 \\
\pm 6.18\end{array}$ & 24.34 & 43.24 & 31.98 & 551.46 & 651.22 \\
\hline 31500 & $\mathrm{C}$ & $\begin{array}{r}28.67 \\
\pm 0.40\end{array}$ & 1.000 & $\begin{array}{r}0.025 \\
\pm 0.004\end{array}$ & $\begin{array}{r}306.1 \\
\pm 6.3\end{array}$ & $\begin{array}{r}24.75 \\
\pm 2.55\end{array}$ & $\begin{array}{r}15.58 \\
\pm 0.98\end{array}$ & $\begin{array}{r}18.26 \\
\pm 0.75\end{array}$ & $\begin{array}{r}16.31 \\
\pm 0.83\end{array}$ & $\begin{array}{r}3.308 \\
\pm 0.014\end{array}$ & $\begin{array}{r}83.55 \\
\pm 4.16\end{array}$ & 20.90 & 24.24 & 23.62 & 532.01 & 609.88 \\
\hline 31500 & D & $\begin{array}{r}26.96 \\
\pm 1.30 \\
\end{array}$ & $\begin{array}{r}1.412 \\
\pm 0.078 \\
\end{array}$ & $\begin{array}{r}0.017 \\
\pm 0.005 \\
\end{array}$ & $\begin{array}{r}310.0 \\
\pm 5.5 \\
\end{array}$ & $\begin{array}{r}18.56 \\
\pm 1.83 \\
\end{array}$ & $\begin{array}{r}14.57 \\
\pm 1.27 \\
\end{array}$ & $\begin{array}{r}15.95 \\
\pm 0.65 \\
\end{array}$ & $\begin{array}{r}16.31 \\
\pm 0.83 \\
\end{array}$ & $\begin{array}{r}3.301 \\
\pm 0.012 \\
\end{array}$ & $\begin{array}{r}92.43 \\
\pm 3.80 \\
\end{array}$ & 17.69 & 19.02 & 23.59 & 536.64 & 597.21 \\
\hline 32000 & A & $\begin{array}{r}46.38 \\
\pm 4.79\end{array}$ & 1.000 & $\ldots$ & $\ldots$ & $\begin{array}{r}20.73 \\
\pm 2.02\end{array}$ & $\begin{array}{r}8.16 \\
\pm 0.93\end{array}$ & $\begin{array}{r}15.51 \\
\pm 0.70\end{array}$ & $\begin{array}{r}16.26 \\
\pm 0.83\end{array}$ & $\begin{array}{r}3.373 \\
\pm 0.017\end{array}$ & $\begin{array}{r}101.49 \\
\pm 6.02\end{array}$ & 25.76 & 47.03 & 33.69 & 553.80 & 662.26 \\
\hline 32000 & B & $\begin{array}{r}67.96 \\
\pm 3.06\end{array}$ & $\begin{array}{r}0.703 \\
\pm 0.047\end{array}$ & $\ldots$ & $\ldots$ & $\begin{array}{r}23.60 \\
\pm 2.56\end{array}$ & $\begin{array}{r}6.53 \\
\pm 0.34\end{array}$ & $\begin{array}{r}15.74 \\
\pm 0.93\end{array}$ & $\begin{array}{r}16.26 \\
\pm 0.83\end{array}$ & $\begin{array}{r}3.417 \\
\pm 0.007\end{array}$ & $\begin{array}{r}92.72 \\
\pm 6.11\end{array}$ & 24.05 & 42.77 & 31.82 & 551.29 & 650.46 \\
\hline 32000 & $\mathrm{C}$ & $\begin{array}{r}28.60 \\
\pm 1.60\end{array}$ & 1.000 & $\begin{array}{r}0.024 \\
\pm 0.002\end{array}$ & $\begin{array}{r}306.0 \\
\pm 6.8\end{array}$ & $\begin{array}{r}24.78 \\
\pm 0.52\end{array}$ & $\begin{array}{r}15.64 \\
\pm 1.46\end{array}$ & $\begin{array}{r}18.29 \\
\pm 0.45\end{array}$ & $\begin{array}{r}16.26 \\
\pm 0.83\end{array}$ & $\begin{array}{r}3.307 \\
\pm 0.016\end{array}$ & $\begin{array}{r}83.42 \\
\pm 3.01\end{array}$ & 20.68 & 23.77 & 23.34 & 532.13 & 609.55 \\
\hline 32000 & $\mathrm{D}$ & $\begin{array}{r}26.97 \\
\pm 1.44 \\
\end{array}$ & $\begin{array}{r}1.411 \\
\pm 0.076 \\
\end{array}$ & $\begin{array}{r}0.017 \\
\pm 0.005 \\
\end{array}$ & $\begin{array}{r}310.0 \\
\pm 5.3 \\
\end{array}$ & $\begin{array}{r}18.56 \\
\pm 1.74 \\
\end{array}$ & $\begin{array}{r}14.56 \\
\pm 1.43 \\
\end{array}$ & $\begin{array}{r}15.95 \\
\pm 0.75 \\
\end{array}$ & $\begin{array}{r}16.26 \\
\pm 0.83 \\
\end{array}$ & $\begin{array}{r}3.301 \\
\pm 0.011 \\
\end{array}$ & $\begin{array}{r}92.43 \\
\pm 4.11 \\
\end{array}$ & 17.70 & 18.91 & 23.48 & 536.62 & 597.03 \\
\hline 32500 & A & $\begin{array}{r}46.32 \\
\pm 5.54\end{array}$ & 1.000 & $\ldots$ & 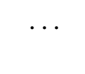 & $\begin{array}{r}20.58 \\
\pm 2.26\end{array}$ & $\begin{array}{r}8.13 \\
\pm 1.32\end{array}$ & $\begin{array}{r}15.50 \\
\pm 0.92\end{array}$ & $\begin{array}{r}16.26 \\
\pm 0.84\end{array}$ & $\begin{array}{r}3.371 \\
\pm 0.019\end{array}$ & $\begin{array}{r}101.30 \\
\pm 7.42\end{array}$ & 25.41 & 46.45 & 33.29 & 553.55 & 660.64 \\
\hline 2500 & B & $\begin{array}{r}67.91 \\
\pm 7.48\end{array}$ & $\begin{array}{r}0.705 \\
\pm 0.058\end{array}$ & $\ldots$ & $\ldots$ & $\begin{array}{r}23.44 \\
\pm 2.67\end{array}$ & $\begin{array}{r}6.50 \\
\pm 0.46\end{array}$ & $\begin{array}{r}15.74 \\
\pm 0.75\end{array}$ & $\begin{array}{r}16.26 \\
\pm 0.84\end{array}$ & $\begin{array}{r}3.414 \\
\pm 0.013\end{array}$ & $\begin{array}{r}92.91 \\
\pm 5.32\end{array}$ & 23.66 & 42.52 & 31.65 & 551.14 & 649.47 \\
\hline 32500 & $\mathrm{C}$ & $\begin{array}{r}28.56 \\
\pm 0.43\end{array}$ & 1.000 & $\begin{array}{r}0.024 \\
\pm 0.002\end{array}$ & $\begin{array}{r}306.0 \\
\pm 5.4\end{array}$ & $\begin{array}{r}24.97 \\
\pm 0.27\end{array}$ & $\begin{array}{c}15.74 \\
\pm 0.26\end{array}$ & $\begin{array}{r}18.36 \\
\pm 0.21\end{array}$ & $\begin{array}{r}16.26 \\
\pm 0.84\end{array}$ & $\begin{array}{r}3.307 \\
\pm 0.005\end{array}$ & $\begin{array}{r}83.58 \\
\pm 1.36\end{array}$ & 20.58 & 23.60 & 23.34 & 532.18 & 609.61 \\
\hline 32500 & D & $\begin{array}{r}26.99 \\
\pm 0.93 \\
\end{array}$ & $\begin{array}{r}1.412 \\
\pm 0.091 \\
\end{array}$ & $\begin{array}{r}0.017 \\
\pm 0.003 \\
\end{array}$ & $\begin{array}{l}310.7 \\
\pm 6.1 \\
\end{array}$ & $\begin{array}{r}18.57 \\
\pm 2.38 \\
\end{array}$ & $\begin{array}{r}14.55 \\
\pm 0.73 \\
\end{array}$ & $\begin{array}{r}15.96 \\
\pm 0.76 \\
\end{array}$ & $\begin{array}{r}16.26 \\
\pm 0.84 \\
\end{array}$ & $\begin{array}{r}3.301 \\
\pm 0.011 \\
\end{array}$ & $\begin{array}{r}92.57 \\
\pm 5.01 \\
\end{array}$ & 17.81 & 19.01 & 23.21 & 536.58 & 596.90 \\
\hline 33000 & A & $\begin{array}{r}46.30 \\
\pm 4.84\end{array}$ & 1.000 & . & . & $\begin{array}{r}20.50 \\
\pm 2.42\end{array}$ & $\begin{array}{r}8.12 \\
\pm 1.44\end{array}$ & $\begin{array}{r}15.50 \\
\pm 0.92\end{array}$ & $\begin{array}{r}16.29 \\
\pm 0.84\end{array}$ & $\begin{array}{r}3.369 \\
\pm 0.020\end{array}$ & $\begin{array}{r}101.27 \\
\pm 5.90\end{array}$ & 25.13 & 46.01 & 32.99 & 553.36 & 659.47 \\
\hline 3300 & B & $\begin{array}{r}67.76 \\
\pm 5.30\end{array}$ & $\begin{array}{r}0.693 \\
\pm 0.049\end{array}$ & $\ldots$ & $\ldots$ & $\begin{array}{r}24.18 \\
\pm 2.07\end{array}$ & $\begin{array}{r}6.63 \\
\pm 0.38\end{array}$ & $\begin{array}{r}15.99 \\
\pm 0.61\end{array}$ & $\begin{array}{r}16.29 \\
\pm 0.84\end{array}$ & $\begin{array}{r}3.413 \\
\pm 0.008\end{array}$ & $\begin{array}{r}92 \\
\pm 5\end{array}$ & 23.57 & 71 & 31.39 & 51.05 & 648.98 \\
\hline 33000 & $\mathrm{C}$ & $\begin{array}{r}28.50 \\
\pm 0.42\end{array}$ & 1.000 & $\begin{array}{r}0.024 \\
\pm 0.002\end{array}$ & $\begin{array}{r}306.9 \\
\pm 5.8\end{array}$ & $\begin{array}{r}25.06 \\
\pm 0.26\end{array}$ & $\begin{array}{r}15.82 \\
\pm 0.31\end{array}$ & $\begin{array}{r}18.40 \\
\pm 0.07\end{array}$ & $\begin{array}{r}16.29 \\
\pm 0.84\end{array}$ & $\begin{array}{r}3.307 \\
\pm 0.005\end{array}$ & $\begin{array}{r}83.59 \\
\pm 1.15\end{array}$ & 20.66 & 23.86 & 22.96 & 532.20 & 609.65 \\
\hline 33000 & $\mathrm{D}$ & $\begin{array}{r}27.89 \\
\pm 1.15 \\
\end{array}$ & $\begin{array}{r}1.386 \\
\pm 0.077 \\
\end{array}$ & $\begin{array}{r}0.020 \\
\pm 0.005 \\
\end{array}$ & $\begin{array}{r}312.0 \\
\pm 5.7 \\
\end{array}$ & $\begin{array}{r}19.87 \\
\pm 2.27 \\
\end{array}$ & $\begin{array}{r}14.42 \\
\pm 1.20 \\
\end{array}$ & $\begin{array}{r}16.34 \\
\pm 0.90 \\
\end{array}$ & $\begin{array}{r}16.29 \\
\pm 0.84 \\
\end{array}$ & $\begin{array}{r}3.310 \\
\pm 0.016 \\
\end{array}$ & $\begin{array}{r}95.95 \\
\pm 6.65 \\
\end{array}$ & 18.56 & 20.65 & 22.32 & 535.30 & 596.86 \\
\hline 3350 & A & $\begin{array}{r}44.04 \\
\pm 2.85\end{array}$ & 1.000 & $\ldots$ & $\ldots$ & $\begin{array}{r}20.66 \\
\pm 2.06\end{array}$ & $\begin{array}{r}8.57 \\
\pm 1.10\end{array}$ & $\begin{array}{r}15.72 \\
\pm 0.63\end{array}$ & $\begin{array}{r}16.32 \\
\pm 0.84\end{array}$ & $\begin{array}{r}3.360 \\
\pm 0.013\end{array}$ & $\begin{array}{r}98.75 \\
\pm 5.62\end{array}$ & 24.97 & 46.15 & 32.96 & 553.02 & 658.01 \\
\hline 33500 & B & $\begin{array}{r}60.52 \\
\pm 7.31\end{array}$ & $\begin{array}{r}0.730 \\
\pm 0.077\end{array}$ & $\ldots$ & $\ldots$ & $\begin{array}{r}24.15 \\
\pm 2.54\end{array}$ & $\begin{array}{r}7.13 \\
\pm 0.76\end{array}$ & $\begin{array}{r}16.21 \\
\pm 0.76\end{array}$ & $\begin{array}{r}16.32 \\
\pm 0.84\end{array}$ & $\begin{array}{r}3.401 \\
\pm 0.014\end{array}$ & $\begin{array}{r}93.14 \\
\pm 5.52\end{array}$ & 23.45 & 42.50 & 31.29 & 551.31 & 648.66 \\
\hline 33500 & $\mathrm{C}$ & $\begin{array}{r}28.49 \\
\pm 2.16\end{array}$ & 1.000 & $\begin{array}{r}0.024 \\
\pm 0.004\end{array}$ & $\begin{array}{r}305.9 \\
\pm 6.1\end{array}$ & $\begin{array}{r}25.07 \\
\pm 1.06\end{array}$ & $\begin{array}{r}15.83 \\
\pm 1.09\end{array}$ & $\begin{array}{r}18.42 \\
\pm 0.22\end{array}$ & $\begin{array}{r}16.32 \\
\pm 0.84\end{array}$ & $\begin{array}{r}3.306 \\
\pm 0.019\end{array}$ & $\begin{array}{r}83.62 \\
\pm 5.56\end{array}$ & 20.61 & 24.09 & 23.06 & 532.27 & 609.97 \\
\hline 33500 & D & $\begin{array}{r}27.81 \\
\pm 0.87 \\
\end{array}$ & $\begin{array}{r}1.398 \\
\pm 0.079 \\
\end{array}$ & $\begin{array}{r}0.019 \\
\pm 0.003 \\
\end{array}$ & $\begin{array}{r}312.0 \\
\pm 5.5 \\
\end{array}$ & $\begin{array}{r}19.70 \\
\pm 2.35 \\
\end{array}$ & $\begin{array}{r}14.42 \\
\pm 1.29 \\
\end{array}$ & $\begin{array}{r}16.28 \\
\pm 0.92 \\
\end{array}$ & $\begin{array}{r}16.32 \\
\pm 0.84 \\
\end{array}$ & $\begin{array}{r}3.309 \\
\pm 0.014 \\
\end{array}$ & $\begin{array}{r}96.13 \\
\pm 5.39 \\
\end{array}$ & 18.56 & 20.64 & 22.30 & 535.26 & 596.80 \\
\hline 34000 & A & $\begin{array}{r}44.04 \\
\pm 2.80\end{array}$ & 1.000 & $\ldots$ & $\ldots$ & $\begin{array}{r}20.63 \\
\pm 1.64\end{array}$ & $\begin{array}{r}8.56 \\
\pm 0.95\end{array}$ & $\begin{array}{r}15.73 \\
\pm 0.66\end{array}$ & $\begin{array}{r}16.34 \\
\pm 0.84\end{array}$ & $\begin{array}{r}3.359 \\
\pm 0.013\end{array}$ & $\begin{array}{r}98.81 \\
\pm 5.24\end{array}$ & 24.73 & 45.69 & 32.69 & 552.78 & 656.84 \\
\hline 34000 & B & $\begin{array}{r}65.32 \\
\pm 7.42\end{array}$ & $\begin{array}{r}0.703 \\
\pm 0.085\end{array}$ & $\ldots$ & $\ldots$ & $\begin{array}{r}24.04 \\
\pm 2.36\end{array}$ & $\begin{array}{r}6.75 \\
\pm 0.50\end{array}$ & $\begin{array}{r}16.08 \\
\pm 0.64\end{array}$ & $\begin{array}{r}16.34 \\
\pm 0.84\end{array}$ & $\begin{array}{r}3.406 \\
\pm 0.016\end{array}$ & $\begin{array}{r}92.80 \\
\pm 5.32\end{array}$ & 23.30 & 42.94 & 31.24 & 550.83 & 648.55 \\
\hline 34000 & $\mathrm{C}$ & $\begin{array}{r}28.38 \\
\pm 2.32\end{array}$ & 1.000 & $\begin{array}{r}0.024 \\
\pm 0.005\end{array}$ & $\begin{array}{r}306.0 \\
\pm 5.1\end{array}$ & $\begin{array}{r}25.06 \\
\pm 0.79\end{array}$ & $\begin{array}{r}15.90 \\
\pm 1.41\end{array}$ & $\begin{array}{r}18.43 \\
\pm 0.55\end{array}$ & $\begin{array}{r}16.34 \\
\pm 0.84\end{array}$ & $\begin{array}{r}3.306 \\
\pm 0.017\end{array}$ & $\begin{array}{r}83.37 \\
\pm 5.88\end{array}$ & 22.29 & 24.31 & 23.01 & 532.23 & 610.29 \\
\hline 34000 & D & $\begin{array}{r}27.83 \\
\pm 0.97\end{array}$ & $\begin{array}{r}1.405 \\
\pm 0.073\end{array}$ & $\begin{array}{r}0.019 \\
\pm 0.003\end{array}$ & $\begin{array}{r}312.0 \\
\pm 5.8\end{array}$ & $\begin{array}{r}19.71 \\
\pm 1.94\end{array}$ & $\begin{array}{r}14.41 \\
\pm 0.61\end{array}$ & $\begin{array}{r}16.27 \\
\pm 0.60\end{array}$ & $\begin{array}{r}16.34 \\
\pm 0.84\end{array}$ & $\begin{array}{r}3.310 \\
\pm 0.013\end{array}$ & $\begin{array}{r}96.62 \\
\pm 5.29\end{array}$ & 18.62 & 20.78 & 22.38 & 535.19 & 597.05 \\
\hline
\end{tabular}

Notes.

${ }^{a}$ The stellar radius derived from the models.

$\mathrm{b}$ The stellar radius derived from the measured parallax and the assumed temperature.

${ }^{c}$ The projected rotational velocity of the O-star derived from the models. The observed value is $95 \pm 6 \mathrm{~km} \mathrm{~s}^{-1}$.

d Model A assumes a circular orbit and synchronous rotation.

${ }^{\mathrm{e}}$ Model B assumes a circular orbit and nonsynchronous rotation.

${ }^{\mathrm{f}}$ Model $\mathrm{C}$ assumes an eccentric orbit and pseudosynchronous rotation.

g Model D assumes an eccentric orbit and nonsynchronous rotation. 


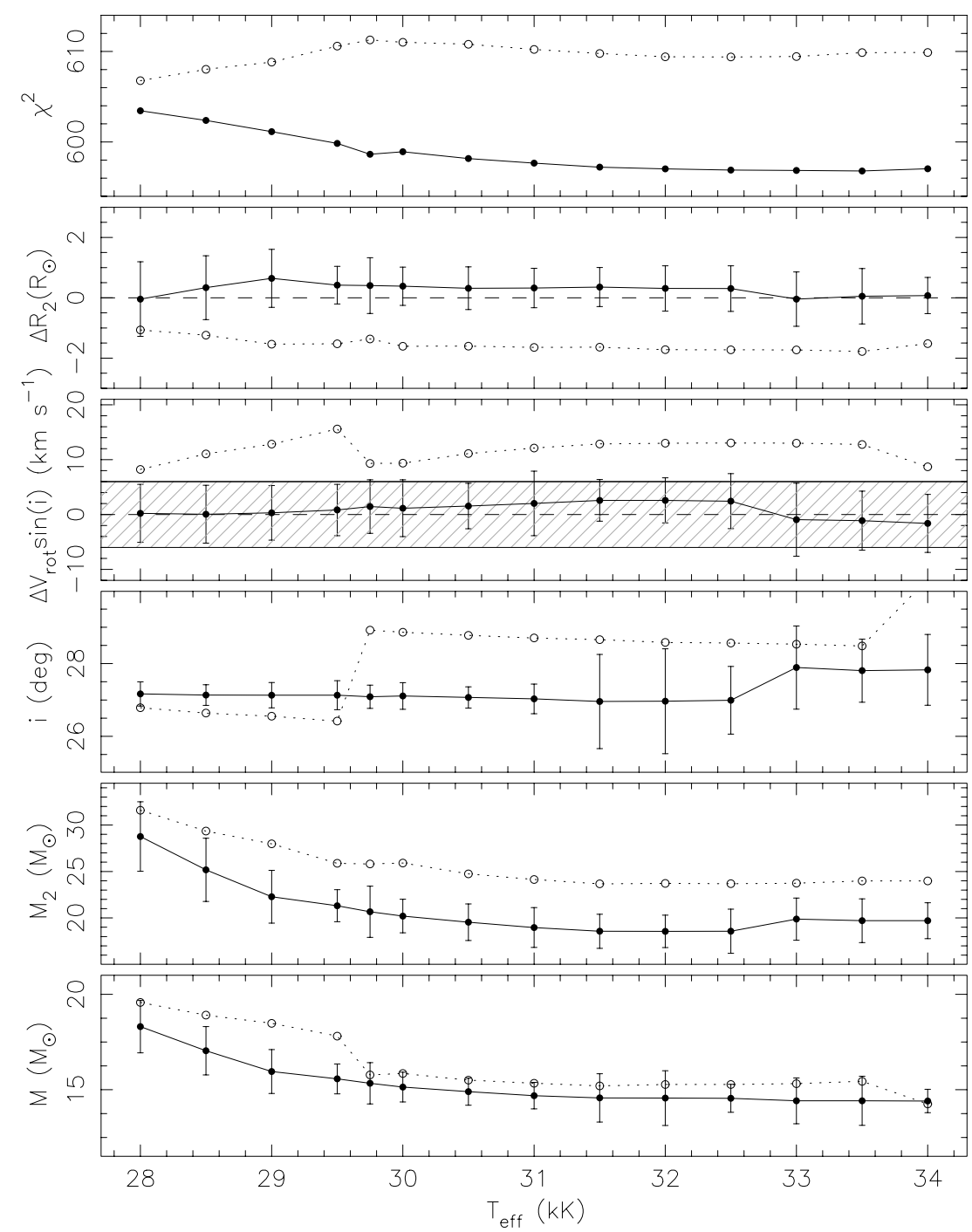

Figure 5. Same as Figure 4, but for the models that assume an eccentric orbit. In this case, the O-star radius derived from the models is larger than the radius derived from the distance, and the derived rotational velocity is smaller than observed.

synchronous model (as in Model C). However, in this case, the model stellar radius $R_{\mathrm{opt}}$ is consistently larger than the radius derived from the distance $R_{\text {dist }}$ and the model rotational velocity is smaller than the observed value. By allowing nonsynchronous rotation in the eccentric orbit (Model D), $R_{\text {opt }}$ agrees with $R_{\text {dist }}$ and the model rotational velocity agrees with the measured value.

\section{REFERENCES}

Abubekerov, M. K., Antokhina, É. A., \& Cherepashchuk, A. M. 2005, Astron. Rep., 49, 801

Aufdenberg, J. P., Hauschildt, P. H., Shore, S. N., \& Baron, E. 1998, ApJ, 498, 837

Bolton, C. T. 1975, ApJ, 200, 269

Brocksopp, C., Fender, R. P., Larionov, V., et al. 1999a, MNRAS, 309, 1063

Brocksopp, C., Tarasov, A. E., Lyuty, V. M., \& Roche, P. 1999b, A\&A, 343, 861

Caballero-Nieves, S. M., Gies, D. R., Bolton, C. T., et al. 2009, ApJ, 701, 1895

Cadolle Bel, M., Sizun, P., Goldwurm, A., et al. 2006, A\&A, 446, 591

Cardelli, J. A., Clayton, G. C., \& Mathis, J. S. 1989, ApJ, 345, 245

Eaton, J. A. 2008, ApJ, 681, 562

Eggleton, P. P. 1983, ApJ, 268, 368

Frontera, F., Palazzi, E., Zdziarski, A. A., et al. 2001, ApJ, 546, 1027

Gierlinski, M., Zdziarski, A. A., Done, C., et al. 1997, MNRAS, 288, 958
Gies, D. R., \& Bolton, C. T. 1986, ApJ, 304, 371

Gies, D. R., Bolton, C. T., Thomson, J. R., et al. 2003, ApJ, 583, 424

Gou, L. J., McClintock, J. E., Reid, M. J., et al. 2011, ApJ, 742, 85

Guinan, E. F., Dorren, J. D., Siah, M. J., \& Koch, R. H. 1979, ApJ, 229, 296

Herrero, A., Kudritzki, R. P., Gabler, R., Vilchez, J. M., \& Gabler, A. 1995, A\&A, 297, 556

Hutchings, J. B. 1978, ApJ, 226, 264

Kalogera, V., \& Baym, G. 1996, ApJ, 470, L61

Karitskaya, E. A., Agafonov, M. I., Bochkarev, N. G., et al. 2005, Astron. Astrophys. Trans., 24, 383

Lanz, T., \& Hubeny, I. 2003, ApJS, 146, 417

Lanz, T., \& Hubeny, I. 2007, ApJS, 169, 83

Ninkov, Z., Walker, G. A. H., \& Yang, S. 1987, ApJ, 321, 425

Orosz, J. A., Groot, Paul J., van der Klis, M., et al. 2002, ApJ, 568, 845

Orosz, J. A., \& Hauschildt, P. H. 2000, A\&A, 364, 265

Orosz, J. A., McClintock, J. E., Narayan, R., et al. 2007, Nature, 449, 872

Orosz, J. A., Steeghs, D., McClintock, J. E., et al. 2009, ApJ, 697, 573

Paczyński, B. 1974, A\&A, 34, 161

Reid, M. J., McClintock, J. E., Narayan, R., et al. 2011, ApJ, 742, 83

Remillard, R. A., \& McClintock, J. E. 2006, ARA\&A, 44, 49

Shaposhnikov, N., \& Titarchuk, L. 2007, ApJ, 663, 445

Skrutskie, M. F., Cutri, R. M., Stiening, R., et al. 2006, AJ, 131, 1163

Trimble, V., Rose, W. K., \& Weber, J. 1973, MNRAS, 162, 1P

Wilson, R. E. 1990, ApJ, 356, 613

Wilson, R. E., \& Sofia, S. 1976, ApJ, 203, 182

Zhang, S. N., Cui, W., Harmon, B. A., et al. 1997, ApJ, 477, L95 